\title{
ZnO materials and surface tailoring for biosensing.
}

Rositza Yakimova, Linnea Selegård, Volodymyr Khranovskyy, Ruth Pearce, Anita Lloyd Spetz and Kajsa Uvdal

\section{Linköping University Post Print}

N.B.: When citing this work, cite the original article.

Original Publication:

Rositza Yakimova, Linnea Selegård, Volodymyr Khranovskyy, Ruth Pearce, Anita Lloyd Spetz and Kajsa Uvdal, ZnO materials and surface tailoring for biosensing., 2012, Frontiers in bioscience (Elite edition), (4), 254-78.

Copyright: Frontiers in Bioscience

Postprint available at: Linköping University Electronic Press http://urn.kb.se/resolve?urn=urn:nbn:se:liu:diva-79152 


\title{
ZnO materials and surface tailoring for biosensing
}

\author{
Rositza Yakimova, Linnea Selegard, Volodymyr Khranovskyy, Ruth Pearce, Anita Lloyd Spetz, Kajsa Uvdal \\ Department of Physics, Chemistry and Biology, Linkoping University, SE-58183 Linkoping, Sweden
}

TABLE OF CONTENTS

\author{
1. Abstract \\ 2. Introduction \\ 3. Controllable wettability of $\mathrm{ZnO}$ nanostructures \\ 4. Biocompatibility and toxicity aspects of $\mathrm{ZnO}$ applications \\ 5. Biofunctionalization of $\mathrm{ZnO}$ materials \\ 5.1. Preparation of $\mathrm{ZnO}$ materials \\ 5.2. Surface cleaning \\ 5.3. Molecular attachment on $\mathrm{ZnO}$ crystal surfaces and nanoparticles \\ 6. Recent achievements in $\mathrm{ZnO}$ nanocrystal based biosensors \\ 7. Summary and perspectives \\ 8. Acknowledgements \\ 9. References
}

\section{ABSTRACT}

$\mathrm{ZnO}$ nanostructured materials, such as films and nanoparticles, could provide a suitable platform for development of high performance biosensors due to their unique fundamental material properties. This paper reviews different preparation techniques of $\mathrm{ZnO}$ nanocrystals and material issues like wettability, biocompatibility and toxicity, which have an important relevance to biosensor functionality. Efforts are made to summarize and analyze existing results regarding surface modification and molecular attachments for successful biofunctionalization and understanding of the mechanisms involved. A section is devoted to implementations of tailored surfaces in biosensors. We end with conclusions on the feasibility of using $\mathrm{ZnO}$ nanocrystals for biosensing.

\section{INTRODUCTION}

Although known and utilized for a very long time, it is only during the last decade that zinc oxide ( $\mathrm{ZnO}$ ) has been the focus of research in relation to promising photonic and electronic applications of this material. As a direct wide band gap (3.37 eV) semiconductor $\mathrm{ZnO}$ is attractive for short-wavelength light emitting devices while, as an oxide semiconductor, it is highly interesting for a range of sensors - from gas sensors to biological sensors. The latter applications are highly promising because $\mathrm{ZnO}$ nanostructures exhibit relevant properties including high catalytic efficiency and strong adsorption ability. Recently, interest has been focused towards applications of $\mathrm{ZnO}$ in biosensors due to its high isoelectric point (IEP) of 9.5, biocompatibility, and abundance in nature (1). The high isoelectric point of $\mathrm{ZnO}$ results in a unique ability to immobilize an enzyme with a low isoelectric point through electrostatic interaction. Furthermore, nontoxicity, high chemical stability and high electron transfer capability make $\mathrm{ZnO}$ a promising material for immobilization of biomolecules without an electron mediator and can be employed for developing implantable biosensors $(2,3)$.

The renewed interest in $\mathrm{ZnO}$ has been driven by the success in growth of single crystals, epitaxial layers and nanostructures with controlled properties. Concomitantly, novel device concepts and implementations emerge, e.g. nanopiezotronics and nanogenerators (4), excitonic solar cells (5 - 7), and probably many more will appear owing to the multifunctional features of $\mathrm{ZnO}$. The nanowire dye-sensitized solar cell (DSC) is an exciting variant of the most successful of the excitonic photovoltaic devices. As an ordered topology that increases the rate of electron transport, a nanowire electrode may provide a means to improve the quantum efficiency of DSCs in the red region of the spectrum, where their efficiency is currently limited (6).

In a single crystal state $\mathrm{ZnO}$ can be prepared as two inch diameter bulk crystals, e.g. (8), thin films $(9,10)$ and distinct nanostructures of large morphological varieties, such as nanobelts (11), nanorods (12,13), distinct nanowires (14), etc. Structural quality and stoichiometry control are key characteristics of materials intended for modern device applications. The availability of single crystal substrates and epitaxial layers of $\mathrm{ZnO}$ promises to realize reliable transducers for high performance bioelectronic devices. The application of nanomaterials to the design of biosensors is nowadays one of the most active research fields due to their high activity, good selectivity, and outstanding specific surfaces (15). One-dimensional single-crystalline ZnO nanostructures have been synthesized successfully in several groups (14, 16 - 19). Such structures exhibit high surface to volume ratios and superior mechanical stability making them ideal candidates for sensors. Gas sensors based on ZnO nanorods and thin films have been reviewed in (20). In a recent review S.J. Pearton and co-authors (21) have illustrated the significance of wide band gap semiconductors, including $\mathrm{ZnO}$, in sensor applications. It is stated for example, that the use of enzymes or adsorbed 
antibody layers on the semiconductor surface leads to highly specific detection of a broad range of antigens of interest in the medical and homeland security fields.

Zh.L. Wang (4) has recently brought to the forefront the significance of $\mathrm{ZnO}$ nanowires and nanobelts in the field of nanotechnology. Furthermore, $\mathrm{ZnO}$ nanowires have been shown to be bio-safe and biocompatible (22) which makes them attractive for applications as implantable biosensors. This opens unexplored possibilities to novel biosensor platforms. Nanoparticles (NPs) and nanostructured films of $\mathrm{ZnO}$ have, through the years, maintained vast research interests and realization in the field of gas sensors (23 - 26) and biomedical sensors (27, 28). Among the advantages of these materials is the ease of preparation while possessing high sensing performance and quantum properties. A comparison of the gas sensing capability of nanoparticles and nanostructured films has been conducted by J. Eriksson and co-authors (29). The investigation was made for oxygen detection in a carrier gas of nitrogen where it was shown that nanoparticles had higher sensitivity. Keeping in mind that the sensing mechanism of semiconducting oxide gas sensors is based on the surface reaction of the semiconducting oxides (30), it is expected that their microstructure is one of the most important factors for high sensitivity, i.e. nanoparticles have an advantage because of their larger surface area. However, in other studies it has been revealed that the aggregation of $\mathrm{ZnO}$ nanoparticles limits the properties of the sensors (31).

Another issue which should be considered when using nanostructured $\mathrm{ZnO}$ materials with a textured structure, i.e. containing grains, is the difficulty in maintaining stoichiometric composition with the concentration of oxygen vacancies $\left(\mathrm{V}_{\mathrm{O}}\right)$ typically increasing. This mainly has an impact on optical properties but, it has also been demonstrated to affect sensor performance (32). In particular, a resistive sensor prototype under oxygen exposure showed a gradual decrease of the conductivity due to oxygen diffusion into the bulk of the films and a subsequent elimination of the oxygen vacancies (as the source of intrinsic charge carriers). The results suggested a suitable pretreatment procedure for improvement of the stoichiometry of the $\mathrm{ZnO}$ films, which is related to the material stability and oxygen sensitivity (32).

Nanoparticles and nanostructured thin films have been studied in terms of their gas sensing abilities, where it was shown that a rough surface with a larger surface area had a positive influence on the sensor response (29). As such, ZnO thin films and $\mathrm{ZnO}$ nanoparticles are both very interesting for electrically based biosensing (1).

A review of the state of the art of $\mathrm{ZnO}$ nanocrystal utilization for enzyme immobilization in electrochemical biosensors has been published recently covering key issues in $\mathrm{ZnO}$ synthesis methods and related features such as biosensor performance and biosensor construction e.g., modified electrodes and enzyme immobilization.. The content of the review is oriented toward biosensing of glucose, hydroperoxide, phenol, cholesterol, uric acid and urea, respectively (33).

In bioscience, the special properties of $\mathrm{ZnO}$ nanoparticles have gradually gained increasing attention. The biocompatibility and fast electron transfer ability allow the nanoparticles to function as a biomimic membrane material with the ability to fix and modify proteins. The advantages of $\mathrm{ZnO}$ nanoparticles may also be applied to develop enzymatic detection devices. (34).

A biosensor often consists of biological recognition elements covalently attached to the transducer. Therefore, the functionalization of the $\mathrm{ZnO}$ surface with selected molecular species is of major importance. Self-assembled monolayers (SAMs) of organosilanes are widely used as a first step for the immobilization of biomolecules on oxidized silicon, e.g., for fabrication of on-chip biodevices $(35,36)$. Systematic investigation on functionalization of diamond surfaces has been reported (37 - 39). Only a few studies have been performed for other wide band gap semiconductor surfaces, including ZnO. Recently, a survey on the concepts and possible applications of direct biofunctionalization of various semiconductors has been reported (40).

The present review highlights potentials of $\mathrm{ZnO}$ nanocrystals, addressing mainly nanoparticles, for biosensing by modifying the surface properties. For comparison, results obtained on nanostructured $\mathrm{ZnO}$ films or/and crystals are, where suitable, brought into consideration. Related issues such as wettability and biocompatibility are also discussed.

\section{CONTROLLABLE WETTABILITY OF ZnO NANOSTRUCTURES}

$\mathrm{ZnO}$ nanomaterials demonstrate specific features that are encouraging for biological applications. In particular, via combining their fundamental material properties and a developed surface, $\mathrm{ZnO}$ nanostructures may possess particular characteristics, such as controllable wettability. Making the sensing area superhydrophilic significantly decreases the analyzed liquid consumption. In the work (41), the nano-QCM was exposed under UV radiation to make the sensing area superhydrophilic. The nano-QCM with the superhydrophilic nano-ZnO surface required only $0.5 \mu \mathrm{l}$ of DI water to cover the entire sensing area, while it was needed to take $16 \mu \mathrm{l}$ for the standard QCM. Moreover, the same nano-QCM device exhibits a tenfold increase in frequency shift in detecting the same $1 \mu \mathrm{l}$ of water from the standard QCM (6.2 $\mathrm{kHz}$ for the nano-QCM and $0.7 \mathrm{kHz}$ for the standard QCM). This enhancement in device sensitivity is attributed to the giant effective sensing area for the liquid sample introduced by the superhydrophilic $\mathrm{ZnO}$ nanotip surface. Thus, wettability control allows decrease the analysing volume and significantly increase the sensitivity of the biosensor. 
The possibility to modify and control the surface wettability of different materials has attracted significant scientific and technological interest. Especially for biological systems and microfluidic systems the hydrophobic and hydrophilic nature of a surface plays a key role in the mediation of a solute (e.g. protein) adsorption and cell adhesion. Also, surface roughness may increase hydrophobicity as observed with superhydrophobicity of self-cleaning surfaces like some plant leaves, e.g., lotus. Such an effect can be desirable for channel flows since it can reduce flow resistance (42-47).

The wettability of $\mathrm{ZnO}$ can be tuned and changed in a wide range - from hydrophobicity to superhydrophilicity by UV irradiation (41 - 50). This wettability change can be further increased in low dimensional $\mathrm{ZnO}$ structures, due to high surface-tovolume ratio. In other words, decreasing the size causes enhance of the water repellence for the as prepared $\mathrm{ZnO}$, but also increase the surface hydrophilicity after ultraviolet irradiation. Such a feature can increase the applications of ZnO nanostructures making them eligible for design of water repellents and hydrophobic coatings, as well as self healing and self-repair materials, synthetic self-healing microvascular material and others (41 - 50).

Wettability is characterized by the contact angle (CA), which is the angle between the solid and liquid surfaces. If the liquid wets the surface, the value of the CA is $0^{\circ}<\theta<90^{\circ}$. When the liquid does not wet the surface, the value of the CA is $90{ }^{\circ}$ $<\theta<180^{\circ}$. A surface is super-hydrophobic, if CA is more than $150^{\circ}$ and super-hydrophilic, if less than $5^{\circ}$. However surfaces with only hydrophobic or hydrophilic properties cannot fulfill the requirements of smart devices. Therefore, surfaces with controllable and reversible wettability are highly desirable, particularly for the effective control of micro or nano-fluid motion (41 - 50).

During the past decade there has been an increasing interest in controlling the wettability of solids, which depends on both the surface energy and roughness. For many applications $(41$ - 43) it would be highly advantageous to be able to dynamically manipulate the behaviour of liquids on surfaces. Hong and co authors (44) reported that, the superhydrophobic surfaces with sufficiently high adhesive force had particular advantages to innovate design of open microfluidic devices for increasing needs of controlled transport of small volume of liquids in biochemical separation, targeted drug delivery, immunoassay, etc.

The research devoted to the wettability of $\mathrm{ZnO}$ has met extreme interest during the last two years, resulting in a number of reports $(45-55)$. Earlier, well ordered $\mathrm{ZnO}$ films have demonstrated reversible switching between super-hydrophobicity and super-hydrophilicity (55), which can be controlled via UV irradiation. This effect is believed to be due to the cooperation of the $\mathrm{ZnO}$ intrinsic properties (surface photosensitivity) and the specific structural arrangement (aligned nanostructure) of the films.

Recently, V. Kekkonen and co authors (46) reported a rewritable wettability on ZnO: the planar films were easily patterned by UV laser into hydrophobic and hydrophilic areas with the CA change from $100^{\circ}$ to $20^{\circ}$. It is expected, that the ability of writing, self erasing, and rewriting of hydrophilic patterns on robust planar inorganic films would allow reusable lab-on-achips and microfluidic systems. E. Papadopoulou and co authors (47) reported reversible wettability on ZnO nanostructured films from hydrophobic to hydrophilic with a change of CA from $100^{\circ}$ to $40^{\circ}$ and with a time delay around 40 minutes. It was suggested that the surface chemistry of $\mathrm{ZnO}$ inherited due to growth conditions plays a significant role. J. Lu and co authors (48) observed the similar range of $\mathrm{CA}$ change for $\mathrm{ZnO}$ films which were prepared by a sol gel technique. Heating or dark storage recovered the original hydrophobicity. However, the time for reverse transition - from hydrophilic to hydrophobic - was observed to be 7 days, which compares to $\approx 60$ minutes for reverse transition. The high surface roughness of the films, prepared by N.Tarwal (49) resulted in superhydrophobicity with a CA of $154^{\circ}$, which was explained by the Cassie-Baxter model (50). J. P. Kar and co authors reported the change of CA from $110 \pm 1^{\circ}$ to $75 \pm 4^{\circ}$ (after 12 minutes of UV irradiation) for arrays of rod shaped $\mathrm{ZnO}$ nanostructures grown on a-, c-, r-plane sapphire. It was proposed that the simultaneous existence of $\mathrm{O}$ and $\mathrm{Zn}$ atoms in (1120) plane plays a vital role on the photoinduced wettability transition (51). This conclusion is in agreement with their previous conclusion that the photo induced wettability transition depends on the surface morphology and the concentration of the oxygen vacancies at the surface (52).

With increasing surface development, the nanostructures demonstrate more pronounced wettability. It was shown that the structures with the most developed surface - nanoneedles - possess the highest hydrophobicity $\left(\mathrm{CA}=135^{\circ}\right)$ in comparison to other structures - nanonails and nanorods with a CA of $112^{\circ}$ and $104^{\circ}$ respectively (52). Moreover, the structure of $\mathrm{ZnO}$ was found to affect the transition time from a hydrophobic to a hydrophilic surface. The shortest time $(\approx 4 \mathrm{~min})$ was observed for $\mathrm{ZnO}$ nanoneedles changing from a CA of $114^{\circ}$ to less then $5^{\circ}(52)$. However, the reverse time of transition to the initial state was 60 hours. Recently, the preparation of intelligent superhydrophobic surfaces based on $\mathrm{ZnO}$ nanorod arrays with a switchable adhesion property was reported (53). The reversible and tuneable wettability of $\mathrm{ZnO}$ was explained due to the cooperation of the adsorption/desorption of surface hydroxyl groups and rearrangement of organic chains on the surface. The hierarchical $\mathrm{ZnO}$ structures were proposed to be the best candidates for the changeable wettability $(54,55)$. The biomimetic hierarchical $\mathrm{ZnO}$ structures were reported to demonstrate a hydrophobic behaviour with a CA of $134^{\circ}$ due to the highly developed surface (54). The special hierarchical structure, consisting of microspheres and nanonets, has demonstrated superhydrophobic behaviour with a $\mathrm{CA}$ of $151^{\circ}(55)$.

We have recently analyzed the wettability of the $\mathrm{ZnO}$ nanostructures of different morphologies and the corresponding $\mathrm{CA}$ change with UV irradiation (56). The wide range $\mathrm{ZnO}$ nanostructures (corrals, cabbages, porous hexagons, sheafs, and open 
sheafs) were prepared via atmospheric pressure chemical vapour deposition (APMOCVD) technique (13). The changes in $\mathrm{ZnO}$ nanostructure morphology were a result of different growth temperatures. It has been observed that both the CA and transition time depend on the shape (morphology) of the $\mathrm{ZnO}$. Firstly, we have observed feature size dependent wettability of $\mathrm{ZnO}$ nanostructures of different morphologies. All as grown samples demonstrated hydrophobic behaviour: the CA was found to increase from $100^{\circ}$ for bulk $\mathrm{ZnO}$ with a flat surface to $124^{\circ}$ for the most surface developed open sheaf morphology. After UV irradiation all the samples were transformed to a hydrophilic surface state. However, the $\mathrm{ZnO}$ structures with the most developed surface $-\mathrm{ZnO}$ open sheafs (Figure 1) demonstrated the fastest time of hydrophobic to hydrophilic transition: the CA was changed from $124^{\circ}$ to $7^{\circ}$ after 10 minutes of irradiation. The dependence of the CA on the UV irradiation time for the $\mathrm{ZnO}$ nanostructures with the most developed surface square is shown in (Figure 2). For other structures with a lower surface area the transition time was slightly longer. Such a feature was explained as being due to the low diameter of the nanoneedles $(\approx 30 \mathrm{~nm})$, which consist of an open sheaf structure [56]. The significant CA change under UV irradiation is a result of the photo catalytic reaction on the $\mathrm{ZnO}$ surface and is influenced by the morphology. For nanosheafs the exposed surface area is larger than other morpholoies and the photo catalytic process affects the surface faster then for other structures.

However, the time of reverse wettability transition in our case is rather high (a few days of storage in dark ambient air), which can be explained by the large number of pores in the sample, into which, water enters whilst in a hydrophilic state.

Reversible and tuneable wettability of $\mathrm{ZnO}$ can be explained by the following mechanism: during irradiation by UV light with a photon energy higher than, or equal to, the band gap of $\mathrm{ZnO}$, electrons ( $\mathrm{e}^{-}$) in the valence band can be excited to the conduction band. The same number of holes $\left(\mathrm{h}^{+}\right)$is simultaneously generated in valence band. Some of the holes can react with lattice oxygen to form surface oxygen vacancies (surface trapped hole), while some of the electrons react with lattice metal ions $\left(\mathrm{Zn}^{2+}\right)$ to form $\mathrm{Zn}^{+}$defective sites (surface trapped electrons). Concurrently, water and oxygen may compete to dissociatively adsorb on these defective sites. The defective sites are kinetically more favourable for hydroxyl groups $\left(\mathrm{OH}^{-}\right)$adsorption than oxygen adsorption. As a result, the surface hydrophilicity is improved, and the water contact angle is significantly reduced (58).

Oxygen adsorption is thermodynamically favourable as oxygen bonds more strongly to defect sites than hydroxyl groups. After hydroxyl adsorption, the surface becomes less thermodynamically stable. The hydroxyl groups adsorbed on the defective sites can be progressively replaced by oxygen atoms when the UV irradiated films were placed in the dark. Heat treatment can accelerate the elimination of surface hydroxyl groups (59). As a result, the surface reverts back to its original state (before UV irradiation) by means of dark storage (or heat treatment), and the wettability is reconverted from hydrophilicity to hydrophobicity (48).

\section{BIOCOMPATIBILITY AND TOXICITY ASPECTS OF ZnO APPLICATIONS}

While conventional $\mathrm{ZnO}$ is considered as a biocompatible and non toxic material, no literature is available on the biodegradability and biocompatibility of $\mathrm{ZnO}$ nanostructures, e.g. nanowires or nanobelts, such information is crucial for the application of $\mathrm{ZnO}$ nanostructures in biosensing. The recent trend for decreasing size complicates the situation even more: in comparison to their bulk counterparts, nanomaterals have an increased surface area and reactivity, which allows them to more easily translocate cell membranes, efficiently bind molecular species, and catalyze chemical reactions (60).

$\mathrm{ZnO}$ nanoparticles are believed to be nontoxic, bio safe, and possibly biocompatible and have been used in many applications in our daily life, such as drug carriers and cosmetics. However, data on this subject is rather scant sometimes controversially reported and requires further investigation. For instance, sunscreen contains nanoparticles of $\mathrm{ZnO}$ or $\mathrm{TiO}_{2}(61)$. The photoactive surfaces of the nanoparticles produce reactive oxygen species (ROS) that can potentially cause oxidative stress to tissues or damage DNA. So far, it has shown that nanoparticles in sunscreen remain on the surface of the skin and do not reach the underlying viable cells. However, because human skin is imperfect, it is not an impenetrable barrier (62). ZnO nanostructures could be used for in vivo biosensing and biodetection, providing they do not degrade in the chosen biological environment and are biocompatible. The most relevant physicochemical characteristics of nanomaterials are considered to be: size, surface chemistry, crystallinity, morphology, solubility, aggregation tendency, homogeneity of dispersions, and turbidity. All of these properties need to be assessed in order to determine their contribution to toxicity (60).

Studying the solubility of $\mathrm{ZnO}$ nanomaterials in biofluids has important implications for their applications in biomedical science. Firstly, $\mathrm{ZnO}$ has the potential to be used for biosensors, where, in order to function in biological systems a reasonable time is required. A device "survival lifetime" of a few hours would be necessary. Secondly, if the $\mathrm{ZnO}$ is lost in the body or in a blood vessel, it can be dissolved by the bio fluid into ions that can be absorbed by the body becoming part of one's nutrition without forming blockages. Zn ions are needed by each one of us every day. Finally, the slow solubility and high compatibility of $\mathrm{ZnO}$ in bio fluid is required for its applications in biology.

Brunner and co authors (63) observed that material solubility strongly influenced the cytotoxic response of a range of oxide nanoparticles, with more soluble compounds such as $\mathrm{ZnO}$ and $\mathrm{FeO}$ showing greater acute toxicity than nanoparticles of extremely low solubility such as $\mathrm{CeO}_{2}$ and $\mathrm{TiO}_{2}$. J. Zhou and co authors (64) reported that the $\mathrm{ZnO}$ can be dissolved by deionized water $(\mathrm{pH} \approx 4.5-5.0)$, ammonia $(\mathrm{pH} \approx 7.0-7.1,8.7-9.0)$, and $\mathrm{NaOH}$ solution $(\mathrm{pH} \approx 7.0-7.1,8.7-9.0)$. The study of the interaction 
of $\mathrm{ZnO}$ wires with horse blood serum shows that the $\mathrm{ZnO}$ wires can survive in the fluid for a few hours before they eventually degrade into mineral ions. This implies that the biosensors made of $\mathrm{ZnO}$ nanomaterial do have time to function. Moreover, once completing the function, the $\mathrm{ZnO}$ wires can eventually dissolve into ions that can be completely absorbed by the body and become part of one's daily nutrition.

However, the solubility of $\mathrm{ZnO}$ was reported to be rather controversial; the rate of dissolution and saturation solubility of $\mathrm{ZnO}$ was found to be similar for bulk $\mathrm{ZnO}$ and nanoparticulate $\mathrm{ZnO}$ (65). Using equilibrium dialysis, the equilibrium solubility of $\mathrm{ZnO}$ was determined as $16 \mathrm{mg} / \mathrm{L}$ ( $\mathrm{pH} 7.6,24^{\circ} \mathrm{C}$ ), which is higher than reported in other scientific literature (66). At the same time, Yang and Xie (67) showed that $\mathrm{Zn}^{2+}$ release rates from zinc and zinc oxide nanoparticles were faster than those from microparticles in the initial stages $(<8$ days) of the experiment. In addition to the kinetics of dissolution, the extent of particle solubility may also be size dependent, with nanoparticles expected to have higher equilibrium solubility than macroscopic particles of the same material (68).

We have investigated the interaction of $\mathrm{ZnO}$ bulk material and nanoparticles with physiological solution. The following samples were used: $\mathrm{ZnO}$ single crystals, as prepared $\mathrm{ZnO}$ nanoparticles and $\mathrm{ZnO}$ nanoparticles, rinsed in $0.9 \%$ of $\mathrm{NaCl}$ solution (in order to remove the $\mathrm{Br}$ contaminating impurity introduced during their preparation). The bulk $\mathrm{ZnO}$ sample (Figure $3 \mathrm{a}$,b) was purchased from $\mathrm{ZnOrdic}$ (70). $\mathrm{ZnO}$ nanoparticles were electrochemically produced under oxidizing conditions by electrical deposition under oxidizing conditions (EDOC) (29). The as prepared particles had uniform size distribution and a high degree of crystallinity (Figure 4). The samples were immersed into a physiological solution $(0.9 \%$ of $\mathrm{NaCl})$ for 7 days. The $\mathrm{pH}$ and elementary composition of the solution was controlled throughout. The solubility of the samples after 7 days $\left(\mathrm{T}=36{ }^{\circ} \mathrm{C}\right)$ was determined. The most prominent effect on the $\mathrm{pH}$ change was observed for the as-grown $\mathrm{ZnO}$ nanoparticles (Figure 5), which, however, may be explained due to the Br solubility, as can be seen from the Tab. 1 . We found the single crystalline material to be practically insoluble toward the solution, while the as-grown nanoparticles, containing $\mathrm{Br}$ as a preparation impurity, had a higher solubility. The rinsed $\mathrm{ZnO}$ nanoparticles (where the $\mathrm{Br}$ content was significantly lower) showed twice as high a solubility as the previous sample, thus demonstrating the interaction of the material with the solution. Presence of other elements $-\mathrm{Ca}, \mathrm{Fe}, \mathrm{Si}, \mathrm{Ag}$, $\mathrm{S}$, is explained by their presence in the initial solution.

In conclusion, we have observed that the $\mathrm{ZnO}$ nanoparticle solubility in physiological solution after 7 days is as low as $0.001-0.002$ mass $\%$, while the $\mathrm{ZnO}$ single crystalline material does not appear to be soluble. The solubility of the nano sized $\mathrm{ZnO}$ material should be taken into account during design of bio related applications.

The potential ecotoxicity of nanosized zinc oxide, synthesized by the polyol process, was investigated using common Anabaena flos-aquae cyanobacteria and Euglena gracilis euglenoid microalgae (72). Via addition of ZnO nanoparticles, the photosynthetic activities of these microorganisms varied with the presence of protective agents such as tri-octylphosphine oxide (TOPO) and polyoxyethylene stearyl ether (Brij-76) which is used to control particle size and shape during ZnO synthesis. In the case of Anabaena flos-aquae, the photosynthetic activity, after addition of $\mathrm{ZnO}$, ZnO-TOPO, and ZnO-Brij-76, decreased progressively due to stress induced by the presence of the nanoparticles in the culture medium. After contact with nanoparticles of $\mathrm{ZnO}$ TOPO, this decrease resulted into the cell death.

On the other hand, an important biological effect of $\mathrm{ZnO}$ nanoparticles has been demonstratred. Recent research revealed the cytotoxic effect of $\mathrm{ZnO}$ nanoparticles against glioma and other tumor cells (73). This motivates the investigations of the anti-cancer properties of zinc oxide nanoparticles as a potential medical interest.

Finally, it is worth noting that the technologies of the material preparation have to be preferably clean and nontoxic to be considered safe. Earlier we have shown that pure and doped $\mathrm{ZnO}$ can be prepared by using non-toxic metalorganic precursor what is rather unusual for the MOCVD of $\mathrm{ZnO}(74)$.

\section{BIOFUNCTIONALIZATION OF ZnO MATERIALS}

\subsection{Preparation of $\mathrm{ZnO}$ materials}

$\mathrm{ZnO}$ nanoparticles for biofunctionalization are typically synthesized via wet chemical processes; see for example (75, 76). In Ref. (77) a study of $\mathrm{ZnO}$ nanoparticle preparation, capping and their subsequent biofunctionalization is presented. ZnO nanoparticles were prepared by the method of electrochemical deposition using a sacrificial zinc electrode under oxidizing conditions. An anode and a cathode consisting of zinc metal and stainless steel $\left(\sim 2 \times 5 \mathrm{~cm}^{2}\right)$ respectively were immersed in a 0.1 $\mathrm{M}$ tetrabutylammonium bromide (TBAB) electrolyte solution containing $300 \mathrm{ml}$ 2-propanol. The electrode voltage was $30-40 \mathrm{~V}$ and the current density at the cathode was approximately $1.5 \mathrm{~mA} / \mathrm{cm}^{2}$. The electrolysis was terminated after $3.5 \mathrm{~h}$. The precipitated $\mathrm{ZnO}$ nanoparticles were washed in 2-propanol three times using centrifugation to remove unbound TBAB molecules and free ions of $\mathrm{Zn}^{2+}$ The washed precipitate was air-dried. (3-mercaptopropyl) trimethoxysilane (MPTS) was used to exchange residual adsorbed $\mathrm{TBAB}$ on the $\mathrm{ZnO}$ nanoparticle surfaces. The $\mathrm{ZnO}$ nanoparticles were dispersed in a $1 \%$ MPTS solution using xylene as solvent. The reaction was refluxed over night at $65^{\circ} \mathrm{C}$ and the precipitated particles were washed three times in xylene by centrifugation followed by one wash in methanol. 
Although nanoparticles are very promising for sensing applications, they may exhibit some problems concerning the reproducibility of the results. A main issue maybe their structural quality, size distribution and agglomeration depending on the preparation conditions, even within one technique. In (Figure 6) and (Figure 7) are shown images of $\mathrm{ZnO}$ nanoparticles prepared by different methods (going clockwise: from aqueous solution (78), by physical vapor condensation (79) and from 2-propanol (80). It is apparent that size, morphologies and crystallinity differ to a large extent.

Tipathi and co-authors (79) have reported that the size of the nanoparticles synthesized by the physical vapour condensation method varies in the range of $40 \mathrm{~nm}$ to $100 \mathrm{~nm}$, and it seems that these nanoparticles contain some impurities and defects. In (81) highly crystalline, defect free $\mathrm{ZnO}$ nanoparticles have been synthesised by the chemical co-precipitation technique. The nanoparticles are of semispherical shape having average particle size $\sim 30 \mathrm{~nm}$. The effect of sonicating time on the morphology of the prepared nanoparticles is also studied. Increasing the sonicating time provides quite spherical well-separated nanoparticles. In study (82) nanoparticle morphology, size and structure are shown to depend on the solvent used during their synthesis.

The examples given above clearly indicate the necessity for better control over nanoparticle quality especially when intended for use in biosensor device architectures.

$\mathrm{ZnO}$ thin films are a suitable model system for the nanoparticle surface and have been studied in due to this property. They are also a promising candidates for potential biosensor applications. $\mathrm{ZnO}$ nanostructured films typically contain grains (40$120 \mathrm{~nm}$ lateral size) which are often monocrystalline with a preferential crystallographic orientation. They have less developed surfaces compared to nanoparticles but still have a large porosity which increases their detection ability as compared to dense single crystal films. There are many techniques to deposit $\mathrm{ZnO}$ nanostructured films but the most reproducible way is by metalorganic chemical vapour deposition (MOCVD). In the paper of Selegard and co authors (77) $\mathrm{ZnO}$ films were prepared at atmospheric pressure by plasma enhanced metalorganic chemical vapour deposition (PEMOCVD). The film preparation was carried out under nitrogen flow where oxygen and acetylacetonate were used as precursors. Film deposition was done at a substrate temperature of $350{ }^{\circ} \mathrm{C}$ and $c$-sapphire was used as the film substrate. The estimated film-thickness was about $200 \mathrm{~nm}$ and the obtained polycrystalline films consisted of grains with the $c$-axis oriented perpendicular to the substrate (83).

In (84) a cholesterol biosensor was developed, where the immobilization of cholesterol oxidase (ChOx) was carried out directly on the surface of the $\mathrm{ZnO}$ nanoporous films. The films were deposited by rf magnetron sputtering technique on gold coated corning glass to serve as a matrix for cholesterol biosensor. The $\mathrm{ChOx} / \mathrm{ZnO} / \mathrm{Au}$ bioelectrode has been found to be sensitive to cholesterol.

Pratima R. Solanki and co authors (85) reported nanostructured zinc oxide film fabricated on indium tin oxide (ITO) using a sol gel technique. The preferred film plane was (002), with a $10 \mathrm{~nm}$ crystallite size. The results indicated the suitability of the film for immobilization of cholesterol oxidase (ChOx).

Yin-Feng Li and co authors (78) proposed a phenol biosensor based on immobilizing tyrosinase to $\mathrm{ZnO}$ nanoparticles. Nano $\mathrm{ZnO}$ in this study was prepared via a hydrothermal method via dispersion in the chitosan solution forming a $\mathrm{ZnO} / \mathrm{chitosan}$ matrix for the fabrication of a sensitive phenol biosensor. Chitosan, a natural polymer product, is derived from chitin via deacetylation with alkali. Its excellent film forming and adhesion ability, together with its nontoxicity and biocompatibility has spurred growing interest in its use for the immobilization of biomolecules $(86,87)$. The proposed use of the $\mathrm{ZnO} /$ chitosan/tyrosinase system was when there is no need to employ electron mediators (78).

To be able to use nanostructures as active components in biosensing devices and as probes for bioimaging they have to be designed and functionalized in order to achieve long term stability and to enable molecular recognition (88 - 90). Various functionalization strategies of nanocrystalline $\mathrm{ZnO}$ especially with focus on how the luminescent properties can be varied using different types of capping has been reported earlier (91 - 93).

In the work of Selegård and co authors (77) functionalization of the $\mathrm{ZnO}$ surfaces was performed. Adsorbed hydrocarbon species was removed before the functionalization procedure by annealing at temperatures up to $600^{\circ} \mathrm{C}$ for $30 \mathrm{~min}$. The contact angle decreased from $\sim 50^{\circ}$ to $\sim 10^{\circ}$ after annealing at $600{ }^{\circ} \mathrm{C}$, clearly indicating that the adsorbed carbon species was removed. The effect of the heating procedure on the $\mathrm{ZnO}$ films was investigated using AFM. (Figure 8) shows the AFM images of $\mathrm{ZnO}$ films thermally annealed for 30 minutes in air at $300-600{ }^{\circ} \mathrm{C}$.

Initially, the as-grown surface has rather rough morphology with a relatively small grain size (Figure 9). The grain size grows as a function of annealing temperature, as expected, due to Oswald ripening. This process has previously been studied in detail, for $\mathrm{ZnO}$ films (94). A smoother $\mathrm{ZnO}$ film is obtained, upon initial thermal annealing at $300{ }^{\circ} \mathrm{C}$ (Figure $9 \mathrm{~b}$ ). The clearly observed smoothing is suggested to be due to elimination of strain inside the film, and to partial melting and redistribution of the grains, consistent with earlier studies, where $300{ }^{\circ} \mathrm{C}$ is reported as the appropriate temperature for decreasing the roughness of the $\mathrm{ZnO}$ film surface (94). Further annealing results in an increased grain size and a well developed morphology is obtained at $500^{\circ} \mathrm{C}$ (Figure 9c). The roughness of the film surface becomes more prominent at higher temperatures, $600{ }^{\circ} \mathrm{C}$ (Figure $9 \mathrm{c}$ ). The 
roughness of the surface is considered an additional advantage. An active surface area increase may possibly result in more efficient sensor abilities.

The XRD diffractograms of both an as-grown polycrystalline $\mathrm{ZnO}$ film, and, an as-synthesized TBAB capped $\mathrm{ZnO}$ nanoparticles, are shown in (Figure 9). The XRD diffractogram of a $\mathrm{ZnO}$ film presented in (Figure 9), exhibits the diffraction pattern characteristic of hexagonal $\mathrm{ZnO}$ with peaks corresponding to the (010), (002), (011) reflections, positioned at $2 \theta=31.7^{\circ}$, $34.4^{\circ}$, and $36.2^{\circ}$, respectively. This is consistent with previously reported results on $\mathrm{ZnO}$ films and $\mathrm{ZnO}$ nanoparticles (29, 91 , 95). The dominating (002) reflection peak indicates film with crystal growth with a preferred orientation along the $c$-axis. The diffractogram of the $\mathrm{ZnO}$ nanoparticles (Figure 9) exhibits reflection peaks positioned at the same angles as in the case for the thin film. The broadening of the reflection peaks is due to the much smaller grain size of the nanoparticles compared to the grain size in the film (29).

TEM measurements were performed to confirm presence of crystalline nanoparticles and to reveal their crystal size and shape. In (Figure 10) a TEM image of as-synthesized TBAB capped nanoparticles is shown. The particles produced by the electrochemical synthesis have an estimated diameter of about $5 \mathrm{~nm}$. (Figure 10) indicates that the particles however tend to aggregate. Highly crystalline particles are observed and are also demonstrated in the inset in (Figure 10), which shows the (002) planes $(d \sim 2.6 \AA)$.

Introducing the $3 \mathrm{~d}$ transition metal $\mathrm{Mn}$ to the $\mathrm{ZnO}$ lattice offers an interesting way to tailor various properties of $\mathrm{ZnO}$. $\mathrm{ZnO}$ nanocrystals uniformly doped with $\mathrm{Mn}$ can have advantages as dilute ferromagnetic semiconductors (96) with characteristic luminescence (97). Solid solubility of $\mathrm{Mn}$ in $\mathrm{ZnO}$ is rather high (more than $10 \mathrm{~mol} \%$ ) which allows fabrication of $\mathrm{ZnO}: \mathrm{Mn}$ with high $\mathrm{Mn}$ content for spintronics applications (98). For exploitation of luminescent and magnetic nanoparticles, such as $\mathrm{ZnO}: \mathrm{Mn}$ in biological systems, nanoparticles require be functionalization with organic compounds. These organic compounds have functional groups which can easily undergo a cross linking procedure with many important types of biomolecules, for example peptides, proteins, antibodies and DNA containing carboxylic and amine groups. Sharda and co authors (99) chose the heteromultifunctional organic stabilizer MSA (mercaptosuccinic acid) which can covalently attach to the nano-ZnO surface and introduce a carboxylic functional group that would allow for biofunctionalization. Uniform biocompatible capping with MSA results in nanoballs of luminescent, magnetic $\mathrm{ZnO}: \mathrm{Mn}$. This procedure opens the way to functionalizing $\mathrm{ZnO}$ with a wide variety of biomolecules (99). All experimental analysis confirmed the Mn incorporation, anchoring of capping agent on nanoparticle surface as well as magnetic behaviour. Surface modification of doped and undoped $\mathrm{ZnO}$ nanoparticles with multifunctional biocompatible organic stabilizer was achieved to make them hydrophilic with an active surface, enabling facile bioconjugation with any ligand. These luminescent, magnetic nanoparticles with biocompatible capping may have diverse applications in such areas as biology, pharmaceuticals and medicine.

\subsection{Surface cleaning}

For successful biofunctionalization $\mathrm{ZnO}$ surface must be thoroughly cleaned before further molecular attachment. This is a sensitive issue in particular for $\mathrm{ZnO}$ because of the strong polarity of the $\{0001\}$ faces. The polar $\mathrm{ZnO}(000 \overline{1})$ and $\mathrm{ZnO}$ (0001) crystal faces (Oxygen terminated and zinc terminated, respectively) are thought to be unstable according to Tasker's rule (100). Whereas the mixed $\mathrm{Zn}$ and $\mathrm{O}$ terminated crystal faces $(10 \overline{1} 0)$ and $(11 \overline{2} 0)$ are thought to be stable. ZnO surfaces are known to strongly adsorb hydroxide and carbon which may stabilize the structure (101). However, persistent contaminations of the surface may not be desirable for subsequent surface modifications. Conventional acid based cleaning treatments are difficult due to the very rapid etching of $\mathrm{ZnO}$. Biofunctionalization benefits from a perfect surface top layer of $\mathrm{OH}$ groups, since this is necessary for silanization, the starting point of most biofunctionalization, while carbon should be avoided.

In order to prepare $\mathrm{ZnO}$ surfaces suitable for biofunctionalization, we have examined cleaning processes including washing in warm ethanol (EtOH) and dry heat treatments (heating in $\mathrm{N}_{2}$ with $20 \% \mathrm{O}_{2}$ ) on single crystal surfaces. XPS and contact angle tests were undertaken to compare the effectiveness of the cleaning methods. Firstly a washing in warm ethanol was carried out whereby the $\mathrm{ZnO}$ crystals were placed in a bath of pure ethanol heated to $78^{\circ} \mathrm{C}$ - just bubbling. After washing for 5 minutes the process was repeated with clean ethanol. The $\mathrm{ZnO}$ crystals were then transferred to acetone and sonicated for 5 minutes before transferring to back $\mathrm{EtOH}$ and repeating the sonication process.

The heat treatments were then carried out on the sonicated samples by placing them in a quartz vessel after blow drying with $\mathrm{N}_{2}$. Synthetic air $\left(\mathrm{N}_{2}\right.$ with $\left.20 \% \mathrm{O}_{2}\right)$ was flowed over the samples during their subsequent heating and cooling in a furnace. The furnace was heated to temperatures of 500 or $700^{\circ} \mathrm{C}$. After the heat treatment, samples were transported in EtOH to contact angle or XPS equipment and blown dry with $\mathrm{N}_{2}$ just before analysis. After each cleaning procedure the samples were left for several days and the contact angle tests were repeated on the dirty substrates before the next cleaning procedure.

Static contact angle tests were preformed on the $\mathrm{Zn}$ terminated and $\mathrm{O}$ terminated faces of single crystal $\mathrm{ZnO}$. Three different areas of each crystal face were compared and the results averaged. Contact angle measurements were undertaken before and directly after each cleaning procedure, with transfer after cleaning to the contact angle equipment in clean EtOH. 
(Figure 11) shows the average contact angle on the unclean samples and after each cleaning procedure. It is seen that the $\mathrm{Zn}$ terminated face has a larger contact angle than the $\mathrm{O}$ terminated face suggesting that the $\mathrm{Zn}$ face has adsorbed more carbon contamination which was supported by XPS data (not shown here). Heat treatment to $500^{\circ} \mathrm{C}$ after cleaning showed no more improvement than the sonicating warm EtOH bath, which indicates that this temperature is not sufficient to remove the carbon species from the surface. Heat treatments at $700^{\circ} \mathrm{C}$ showed a very low contact angle which is difficult to measure due to greater amount of droplet spreading. The spreading of the droplet shows effective removal of carbon from the surfaces.

\subsection{Molecular attachment on $\mathrm{ZnO}$ crystal surfaces and nanoparticles}

Covalent attachment of specific biomolecules on $\mathrm{ZnO}$ surfaces is highly important for the realization of a biosensor based on molecular recognition. Equally important is the establishment of a highly stable and well controlled organic/inorganic interface. Detailed research works have to be executed to understand the structure and electronic properties of inorganic/organic hybrid systems on different materials for specific purposes.

One type of interesting candidates for covalent surface modification and stabilization of the $\mathrm{ZnO}$ nanostructures is organosilanes. The silane molecules can bind via covalent siloxane bonds to the metal oxide surface, creating a shielding barrier of cross linked silanes (polysiloxanes) $(103,104)$. This capping serves to inhibit decomposition in aqueous media. When functional organosilanes containing, for example, amines or thiols are chosen, the silanes can also be used in further coupling steps. The silanes hence acts as anchors on the $\mathrm{ZnO}$ material to which a wide range of recognition molecules can be bound, enabling molecular recognition. Functionalization of $\mathrm{ZnO}$ films with biomolecules has been investigated earlier (105). Silanization of $\mathrm{ZnO}$ samples using Aminopropyltriethoxysilane (APTES) was performed. A thin organic film on the $\mathrm{ZnO}$ was prepared by placing the surfaces in a sealed chamber together with 200 microliter APTES and further treated according to the selected procedure (105). The molecular structure formula of APTES is shown in (Figure 12) (left). In a second step, Mercaptopropionic acid (MPA) was linked to the APTES functionalized surface through the terminating $\mathrm{NH}_{2}$ group of APTES. The samples were then placed directly in the XPS instrument. This two step functionalization strategy, binding MPA through an amide bond formation between the amine group of APTES and the carboxylic group in MPA on ZnO epilayer, is used as a proof of concept for biofunctionalization of $\mathrm{ZnO}$ surfaces.

The core level XPS S (2p) spectra of the ZnO epilayer before and after functionalization are presented in Figure 12 (right). No sulphur could be detected on $\mathrm{ZnO}$ epilayer before functionalization, as expected. After the reaction with APTES and MPA, a distinct double peak characteristic for spin orbit coupling i.e. $S 2 p_{3 / 2}$ and $S 2 p_{1 / 2}$ was obtained. The $S(2 p 3 / 2)$ peak was found at $164.5 \mathrm{eV}$. This binding energy position is in a good agreement with binding energies earlier reported for presence of the SH group (106). It should be noted that a small amount of nitrogen was present in the sample before functionalization, which might be due to a primordial reaction of the oxygen terminated surface with nitrogen from the growth ambient. A clear increase of the nitrogen signal is observed after functionalization and the appearance of sulphur after reaction with APTES and MPA verify a successful two step functionalization of the $\mathrm{ZnO}$ film. It should be mentioned here that in that study, it was for the first time indicated that the presence of carbon on the surface of the bulk sample, taken as a comparison, hindered biofunctionalization. The conclusion was that the morphology and the purity on the semiconductor surface is of major importance for successful functionalization.

Immobilization of mercaptopropyl trimethoxysilane (MPTS) based SAMs on ZnO surfaces is reported in (107, 108). $\mathrm{ZnO}$ epilayers, with a thickness of $280 \mathrm{~nm}$, were grown on $c$-plane sapphire substrates by plasma assisted molecular beam epitaxy. The chemical composition, molecular orientation, binding strength to substrate, molecular distribution and wettability were investigated using X-ray photoelectron spectroscopy (XPS), atomic force microscopy (AFM), and contact angle goniometry. Surface functionalization using a thiolated phosphotyrosine analog on the MPTS modified surfaces is also demonstrated. Formation of self assembled monolayers of MPTS is confirmed by XPS and AFM. The core level XPS S (2p) and Si (2p) spectra before and after functionalization are presented in (Figure 13). The presence of both S and Si after MPTS exposure indicates the presence of the organosilane on the $\mathrm{ZnO}$ surface. The MPTS molecular attachment on the surface is proven by the identification of: (i) the silanol $(102.5 \mathrm{eV})$, (ii) the thiolate $(161.5 \mathrm{eV})$, and (iii) small number of molecules through the sulfonate $(168 \mathrm{eV})$ groups. Strong interaction between the thiol and the zinc and/or oxygen sites is in good agreement with earlier studies of octanethiol adsorbed on $\mathrm{ZnO}$ single crystal surface, reported by Pesika co authors (109).

The adsorption of the MPTS molecules on $\mathrm{ZnO}$ surfaces was investigated in detail, similar chemistry as for silanisation of hydroxylated $\mathrm{SiO}_{2}$ surfaces (110), was obtained see (Figure 14). The first step of the mechanism is hydrolysis of alkylsiloxane in either the solvents, or, on the hydroxylated surface. The second step is dehydration on the surfaces. This results in attachment of silanes to the hydroxylated sites, similar to the earlier described mechanism, and thiolate formation on the $\mathrm{Zn}$ sites of the surface. The molecular films are formed on the surfaces linked to the surface through the silane groups with the free thiol groups available for further linking steps. It should be noted that a fraction of the molecules are chemisorbed via the thiolate on the $\mathrm{ZnO}$ surface.

One strategy for further linking procedures is to covalently link a thiolated molecule on the surface by formation of disulfide bridges. This is demonstrated by linking an amino acid derivative, i.e., phosphotyrosine derived thiol (phosphorylated tyrosine propanethiol, pTyr-PT), to the MPTS functionalized $\mathrm{ZnO}$ surfaces. A schematic drawing of such linking procedure is 
shown in (Figure 15). Malemide coupling strategy is another strategy available for biomolecular systems with such functionality present. Both these strategies, based on covalently attachment of biomolecules to MPTS functionalized surfaces, are valuable for biomolecular surface modification and bioelectronics with potential also for biosensor applications.

In some cases, due to different surface activity, the $\mathrm{ZnO}$ molecule interactions may depend on the specific crystalline surfaces, as discussed in paragraph 5.1. P. W. Sadik and co authors (111) used long chain thiol chemistry to functionalize both the $\mathrm{O}$ - and $\mathrm{Zn}$-terminated faces of $\mathrm{ZnO}$. The authors investigated the adsorption of dodecanethiol on the surfaces. A strong enthalpic adsorption is demonstrated by the stability of sulfur on both $\mathrm{ZnO}$ surfaces up to 350 and $400{ }^{\circ} \mathrm{C}$ for oxygen terminated and zinc-terminated substrates, respectively. The minimal presence of the $\mathrm{S} 2 p 3 / 2170 \mathrm{eV}$ peak indicates absorption of the sulfur as an unoxidized thiol. Besides XPS reflection high energy electron diffraction (RHEED) measurements were used on both treated substrates to further characterize the thiol absorption. The Zn-terminated and O-terminated substrates show an equivalent surface ordering in their untreated state, as seen in (Figure 16). After thiol exposure and thermal treatment of the substrates to 250 ${ }^{\circ} \mathrm{C}$, the zinc terminated substrate revealed an amorphous pattern. However, the thiol functionalized oxygen terminated substrate showed some degree of surface order even after thiol treatment. This suggests that, though the surface coverage is lower, the oxygen surface absorbs the thiol in a more ordered fashion with the zinc surface being less ordered (111).

In (112) nanoparticle biofunctionalized was achieved by conjugating a biomolecule via N-hydroxysuccinimide (NHS) to 2-aminoethyl-amino-propyltrimethoxysilane (AEAPS) coated nanoparticles. However, in the presence of water, by time, the NHS ester hydrolyzes, which will result in a less efficient conjugation. Selegård and co authors (77) have shown an alternative coupling strategy for functionalization of $\mathrm{ZnO}$ nanoparticles and $\mathrm{ZnO}$ thin films, which do not suffer the risk of deactivation. An iodized biotin (iodoacetyl-PEG2-biotin) is linked to the thiol group of the bifunctional (3-mercaptopropyl)trimethoxysilane MPTS molecule resulting in a complex herein named MPTS/PEG2-biotin, schematically depicted in (Figure 17). The aim of the study was to investigate the efficiency of the coupling chemistry of critical importance for surface modification procedures and for sensor applications.

The efficiency of the coupling process was investigated using X-ray photoelectron spectroscopy (XPS) and near edge $\mathrm{X}$-ray absorption fine structure (NEXAFS). ZnO nanoparticles and thin films were both found to be successfully functionalized with MPTS as strong peaks in the Si (2p) and S (2p) core level XPS spectra was observed after attachment of MPTS. The conjugation of iodoacetyl-PEG2-biotin to the MPTS capped nanoparticles and thin films was confirmed measuring XPS N (1s). The XPS N (1s) core level spectra showed an increased signal after coupling of iodoacetyl-PEG2-biotin to MPTS in good agreement with PEG2-biotin conjugation to MPTS (Figure 18). This result was also confirmed with NEXAFS spectroscopy as peaks correlated to amide bonds within the MPTS/PEG2-biotin was observed in the N K-edge and O L-edge NEXAFS spectra. The MPTS/PEG2-biotin functionalized nanoparticles and thin films are potential candidates for sensor applications in the future.

Antibody immobilization methods were investigated by Corso and co authors (113) for functionalization of the $\mathrm{ZnO}$ surface. Two different silane molecules were used: (3-glycidyloxypropyl) trimethoxilane (GPS) and (3-mercaptopropyl) trimethoxilane (MPTS). It was concluded that the MPTS is a viable option for moving forward in functionalization of ZnO based sensors due to the fact that it is commercially available chemical and provides high antibody surface coverage with good uniformity.

\section{RECENT ACHIEVEMENTS IN ZNO NANOCRYSTAL BASED BIOSENSORS}

$\mathrm{ZnO}$ based biosensing has been a hot issue for the last few decades, which is confirmed by the number of publications and some new key review papers (114 - 115). The research efforts on this topic recently yielded a number of biosensing devices (115, 116). By detecting traces of associated molecules, it is possible to diagnose diseases and genetic disorders, prevent potential bioattack, and monitor the spread of viruses and pandemics (117-119).

Among the variety of biodevices, the acoustic wave biosensors, mainly surface acoustic wave (SAW) sensors, are considered to have great potential. SAW devices are mass transducers and have the potential for increased detection sensitivity when operated in a specific mode. Acoustic wave based technologies have some advantages over other bio sensing technologies (surface plasmon resonance, optical fibers, sensors based on field effect transistors or cantilever-based detectors), such as: signal simplicity, high sensitivity, compact size, low cost, and massive optical detection systems are not necessary (115). Recently, there has been an increasing interest in SAW based biosensors to detect a versatile range of objects: DNA, enzymes, antibodies, cells and microorganisms, animal and plant cells, cancer cells, biochemical substances or viruses etc. (119 - 121).

The simplest acoustic wave based biosensors is QCM (quartz crystal microbalance). Being able to operate in liquids, it possesses some disadvantages such as a low mass detection limit and large mass which requires a thick substrate and rather large surface area (122). This can be avoided in SH/SAW devices, where the waves propagate in a shear horizontal mode, thus do not dissipate the energy into the liquid media, providing high sensitivity (123). Figure 19 represents a schematic of the ZnO based SAW device, operating in the shear horizontal $(\mathrm{SH})$ surface acoustic waves mode. 
A SAW device based on $\mathrm{ZnO}$ films on $\mathrm{Si}$ was used for sensing the PSA antibody antigen immuno reaction as a function of PSA concentrations (124). The resonance frequencies of the device were found to shift to lower frequencies as the PSAs are specifically immobilized on the surface. Finally, the linear dependence was found between the resonance frequency change and the PSA/ACT complex concentrations over the range of $2-10,000 \mathrm{ng} / \mathrm{ml}(125)$. For the measurements in liquids the SAW devices working in so called SH or Love modes are most promising. For a Love wave mode the shear wave velocity in the surface wave guide layer must be smaller than that in the piezoelectric substrate. A ZnO shear wave velocity is $2578 \mathrm{~m} / \mathrm{s}$, whereas those of ST cut quartz and $\mathrm{SiO}_{2}$ are 4996 and $3765 \mathrm{~m} / \mathrm{s}$, respectively. Thus, it is reasonable to use $\mathrm{ZnO}$ as a guiding layer on substrates of ST cut quartz to form Love mode biosensors. The other potential substrate materials for Love mode $\mathrm{ZnO}$ sensors include $\mathrm{LiTaO}_{3}, \mathrm{LiNbO}_{3}$ and sapphire. A ZnO Love mode device of $\mathrm{ZnO} / 90$ deg rotated ST cut quartz has a maximum sensitivity up to $-18.77 \times 10^{-8} \mathrm{~m}^{2} \mathrm{~s} \mathrm{~kg}^{-1}$, which is much higher than that of a $\mathrm{SiO}_{2}$ /quartz Love mode SAW device (126 - 128). The performance of the devices on lower cost substrates, such as $\mathrm{Si}$, was observed to be even better, having a device sensitivity as high as $8.64 \mu \mathrm{m}^{2} / \mathrm{mg}$, which is up to 5 times higher then on the $\mathrm{LiTaO}_{3}(129,130)$. The polymer substrates (such as PMMA, polyimide, SU-8 or parylene $\mathrm{C}$ ) were reported to be convenient for $\mathrm{ZnO}$ based Love mode sensor with a $\mathrm{ZnO}$ guiding layer.

Similar are the Lamb wave devices, where the wave propagation velocity in the membrane is slower than acoustic wave velocity in the fluids on the surface. Thus, the energy is not dissipating into liquids (131). The negative aspects of the Lamb wave biosensors are the low sensitivity (as a result of low operational frequency) and the fragility of the membrane structures, complicating it performance. However, a $\mathrm{ZnO}$ based Lamb wave sensor was used for monitoring of growth of bacterium "Pseudomonas putida" in toluene, and the reaction of antibodies in an immunoassay for an antigen present in breast cancer patients $(115,132)$. A sensitivity as high as $8.52 \times 10^{7} \mathrm{~cm}^{2} / \mathrm{g}$ at a wave frequency of $9 \mathrm{MHz}$ was reported for the $\mathrm{ZnO}$ based Lamb wave sensor during detection human IgE based on conventional cystamine SAM technology (133).

An optional design is the film bulk acoustic resonator (FBAR) device, which consists of a sub micrometer thick piezoelectric film membrane located between two metallic layer electrodes $(134,135)$. Having a smaller size, high power tolerance and high sensitivity, it has attracted attention in the research field. FBAR based on ZnO allows higher energy densities, enabling increases in the frequency of the device and therefore, a significant decrease of the device area in comparison to SAW or QCM devices.

Thus, in terms of FBAR biosensors, $\mathrm{ZnO}$ has many advantages over other materials. A FBAR based on a $\mathrm{ZnO}$ film was used for detection of DNA and protein molecules at operational frequency $2 \mathrm{GHz}$, providing the sensitivity of $2400 \mathrm{Hzcm} 2 / \mathrm{ng}$ (136). This is three orders of magnitude higher then for the conventional QCM device. Recently, a sensitivity as high as 3654 $\mathrm{kHzcm} 2 / \mathrm{ng}$ was reported for $\mathrm{ZnO}$ based FBAR (137).

Fluorescence detection is another attractive method in the area of biosensing. Using model protein and nucleic acid systems, Dorfman and co authors (138) have demonstrated that tailored nanoscale zinc oxide structures can significantly enhance the detection capability of biomolecular fluorescence as compared to other substrates such as silicon, quartz or polymer. This ultrasensitive detection resulted from the $\mathrm{ZnO}$ nanomaterials which contributed to the increased signal-to-noise ratio of biomolecular fluorescence.

A critical issue in developing a high performance biosensor is to find a simple and reliable process for functionalization of the $\mathrm{ZnO}$ surface through a covalent method to form a robust immobilization of appropriate probe molecules. Particularly, the direct immobilization on the $\mathrm{ZnO}$ film has its advantages for bio sensing applications. Therefore, the surface treatment plays an important role on the applicability of $\mathrm{ZnO}$ for biosensing. Also, growth related characteristics, such as $\mathrm{ZnO}$ film texture, maybe crucial for the piezoelectric and acoustic wave properties of the acoustic devices. The substrate has significant influences on nucleation, growth and texture, acoustic wave velocity/frequency, and electro-mechanical coupling coefficient of the $\mathrm{ZnO}$ acoustic wave devices (115).

For FBAR type biosensor, the film texture is of great importance. In other words, the normally textured $\mathrm{ZnO}$ film (0001) can not be used for sensing in liquid. ZnO normally crystallizes in a hexagonal, wurtzite type structure, with three dominating crystal planes: $\left(\begin{array}{llll}0 & 0 & 0 & 1\end{array}\right),\left(\begin{array}{ll}10^{-} & 10\end{array}\right)$ and $\left(\begin{array}{ll}11^{-} & 20\end{array}\right)$ due to their lowest surface energies (139). SAW devices, based on $\mathrm{ZnO}$ with a (0001) film texture can be used for sensing in air or gases. However, for detection in liquids, generation of the shear horizontal mode wave is necessary, being displaced within the plane of the crystal surface (117). In order to fulfil this requirement, other film textures are necessary: (11-20), (10-10). Such a $\mathrm{ZnO}$ surface can be obtained via substrate influence, resulting in epitaxial growth. $\mathrm{ZnO}$ films were reported to be epitaxially grown with a preferred (not 0001 ) orientation on $\mathrm{Al}_{2} \mathrm{O}_{3}$, AlN etc (140). Other types of the texture control were recently reported, such as, epitaxial growth on a specific substrate, sample position (141), precursor flux control, substrate tilting and using an external oxygen ion source to control the oxygen ion bombardment during growth $(118,142,143)$. Earlier, we demonstrated the change of the texture of the $\mathrm{ZnO}$ films from (0001) to (10-11) via Ga doping and the morphology control via respective annealing (144, 145). We have recently reported on the control of $\mathrm{ZnO}$ nanostructure location and inclination via respective substrate miss cut in the epitaxial growth of $\mathrm{ZnO}$ on $4 \mathrm{H}-\mathrm{SiC}$ (13). Such an approach can be utilized for fabrication of the active $\mathrm{ZnO}$ elements for biosensors, being able for operation in liquid. 
Thus, other (for ex. (11-20)) textured films must be used with little damping effect in a liquid. In ref. (146) the $\mathrm{ZnO}$ based FBAR was fabricated using a $\mathrm{ZnO}$ film with $16 \mathrm{deg}$. off c-axis crystal orientation. It demonstrated $585 \mathrm{Hzcm}^{2} / \mathrm{ng}^{2}$ and mass detection limit of $2.3 \mathrm{ng} / \mathrm{cm}^{2}$ for an avidin/anti avidin biorecognition system (147). The schematic of the FBAR biosensor based on c-axis inclined $\mathrm{ZnO}$ is presented on the Figure 20.

It is noteworthy, that $\mathrm{ZnO}$ bulk materials are expensive and less easily integrated with electronics for control and signal processing. Piezoelectric thin films such as $\mathrm{ZnO}$ have good piezoelectric properties, a high electro mechanical coupling coefficient and high sensitivity and reliability (148). Moreover, 1D ZnO nanostructures were recently investigated and developed to be utilized as e.g. enzyme modified biosensors; they revealed better sensitivity, lower limit of detection in comparison to $\mathrm{ZnO}$ bulk and films based devices $(149,138)$. Recently, Lei and co authors (150) demonstrated a glucose electrochemical biosensor fabricated on $\mathrm{ZnO}$ nanorods, using two approaches: a grown and a transferred active layer. The results demonstrated that an array of well aligned as-grown $\mathrm{ZnO}$ nanorods possesses better sensitivity, response time, detection limit and output signal linearity range. Therefore, it was concluded that directly grown $\mathrm{ZnO}$ nanostructures will have more promise in applications for enzymatic immobilization and signal transduction in the high performance biosensors.

Additionally, we would like to mention such requirements for $\mathrm{ZnO}$ based $\mathrm{SAW}$ as the material ambient and temperature stability. Currently, there is one concern that $\mathrm{ZnO}$ film is very reactive, and unstable even in air or moisture (32). Therefore, the stability and reliability may be a problem. To solve it, an appropriate surface treatment should be performed. For instance, deposition of a thin protection layer such as DLC or $\mathrm{Si}_{3} \mathrm{~N}_{4}$ on top of the $\mathrm{ZnO}$ film may be an optional solution. Alternatively, an "island" ZnO SAW structure as mentioned earlier can be used in order to avoid direct contact between the ZnO active layer and the fluid being pumped (151).

Krishnamoorthy and co authors (152) stated that the $\mathrm{ZnO}$ surface, due to its reactivity, is an effective template for protein immobilization. Later a Love type SAW device biosensor was realized on a $\mathrm{ZnO} / \mathrm{SiO}_{2} / \mathrm{Si}$ structure for the detection of interleukin-6 (IL-6) (153). The biosensor was operating at $747.7 \mathrm{MHz}$ and $1.586 \mathrm{GHz}$, and the $\mathrm{ZnO}$ surface was functionalised through immobilization of IL-6 via direct absorption as well as covalent binding on gluteraldehide. The biosensor was reported to be fully integrated with the CMOS Si chips and to be developed as a portable real time detection system for the interleukin family of proteins in a human serum.

Despite the demonstrated success of sensors based on the gravimetric principle (QCM ,SAW, FBAR), low molecular weight analytes can be difficult to detect based on mass addition alone. The possible solution is the use of mass labels such as gold nanoparticles, which can be used in the context of an assay where free analyte is displaced with a mass-labelled or surface bound version of the molecule. In the latter case, additional amplification is achieved by appending the mass label to the receptor. In the work (154) the use of effector dependent ribozymes (aptazymes) as reagents for augmenting small ligand detection on a mass sensitive device is presented.

Due to photoconductivity and photocatalytic activity of $\mathrm{ZnO}$, enzymatic biosensors based on $\mathrm{ZnO}$ nanoparticles which possess high selectivity and quick response were reported. It was reported that, under exposure to sunlight or ultraviolet radiation, electron/hole pairs are released which can assist the catalytic reactions of enzyme electrodes. For glucose sensors based on $\mathrm{ZnO}$ nanoparticles, the current response was reported to increase up to $30 \%$ at irradiation by the UV light, as well as detection limit lowering by two orders of magnitude in comparison to the dark operating device (80).

The poor electrochemical behaviour of $\mathrm{ZnO}$ was reported to be an obstacle for realization of an integrated third generation biosensors (155). It was explained that due to the absence of the redox couple in $\mathrm{ZnO}$, a mediator is required to provide the shuttling path for electrons, generated in biochemical reactions. The Fe implanted $\mathrm{ZnO}$ thin films were demonstrated as a successful approach for introducing redox centres along with shallow donor levels and therefore resulted in enhanced electron transfer properties. The $\mathrm{GOx} / \mathrm{Fe}-\mathrm{ZnO} / \mathrm{ITO} /$ glass structures were shown to be sensitive to glucose with an enhanced response of $0.326 \mu \mathrm{A} \mathrm{mM}^{-1} \mathrm{~cm}^{-2}$ and a low $\mathrm{Km}$ of $2.76 \mathrm{mM}$. It was concluded that the Fe implanted $\mathrm{ZnO}$ films provide a suitable platform for immobilization of biomolecules and are proving to be a promising third generation biomatrix which could lead to development of MEMS and ISFET based miniaturized biosensors (155).

Recently, Pradhan and co authors (156) demonstrated the performance of a light weight, flexible glucose sensing bioelectrode based on $\mathrm{ZnO}$ NWs electrochemically deposited on a Au coated PET substrate. Using an amperometric method, the $\mathrm{GO}_{\mathrm{x}} / \mathrm{ZnO}-\mathrm{NWs} / \mathrm{Au} / \mathrm{PET}$ bioelectrode was found to exhibit excellent glucose sensing, with a high sensitivity of $19.5 \mu \mathrm{AmM} \mathrm{mM}^{-1} \mathrm{~cm}^{-}$ ${ }^{2}$ and a low Michaelis-Menten constant of $1.57 \mathrm{mM}$, proving $\mathrm{ZnO} \mathrm{NW}$ based biosensors are promising candidates for future commercialization.

By using $\mathrm{Co}$ doped $\mathrm{ZnO}$ nanoclusters an amperometric sensor was realized as a platform for glucose oxidase immobilization (157). Due to the combination of the large specific surface area and high electrocatalytic activity of the $\mathrm{ZnO}$ :Co nanoclusters, the biosensor revealed a high sensitivity of $13.3 \mu \mathrm{A} / \mathrm{mM} \mathrm{cm} \mathrm{cm}^{2}$ for glucose detection and low detection limit of $20 \mu \mathrm{M}$. It was noticed that some species, such as uric acid and ascorbic acid, cannot be completely removed for the biosensor at the operating potential. Possible applications of such biosensors were proposed for environmental and industrial monitoring. 
It was recently reported (116) that the nanostructured $\mathrm{ZnO}$ with its unique properties could provide a suitable microenvironment for immobilization of enzymes while retaining their biological activity, and thus lead to an expanded use of this nanomaterial for the construction of electrochemical biosensors with enhanced analytical performance. In the review (116) the $\mathrm{ZnO}$ based enzyme electrochemical biosensors are well described according to the target biosensing analyte (glucose, hydrogen peroxide, phenol and cholesterol), respectively. Moreover, recent developments in enzyme electrochemical biosensors based on $\mathrm{ZnO}$ nanostructures are reviewed with an emphasis on the fabrication and features of $\mathrm{ZnO}$ appropriate for biosensor construction (e.g., modified electrodes and enzyme immobilization) and biosensor performances (116).

Other aspects of $\mathrm{ZnO}$ based biosensor design are not covered in this review because of size limitations. The aforementioned surface modification is useful also for possible microfluidic applications of $\mathrm{ZnO}$ films however, it is not included in the present paper and can be found elsewhere (115).

\section{SUMMARY AND PERSPECTIVES}

A survey of results on $\mathrm{ZnO}$ nanoparticle and nanostructured film synthesis and tailoring of their surface properties towards biosensor applications has been made. Biocompatibility and biosafety issues have been addressed and important biological effects of $\mathrm{ZnO}$ nanoparticles have been pointed out. The wettability of $\mathrm{ZnO}$ nanostructures of different morphology and their switching from hydrophilic to hydrophobic behaviour has been discussed including the results of UV irradiation. The adsorption of biofunctional molecules along with further molecular bridging has been demonstrated thus indicating a path for biomolecular immobilization. The confirmed covalent bonding of organosilanes on $\mathrm{ZnO}$ surfaces puts forward the possibility of reliable biosensor design while the observed difference in the molecular ordering on the O-and $\mathrm{Zn}$ terminated faces suggests advantages of using nanocrystalline material. Biosensor applications have been reviewed with a focus on surface acoustic wave devices, although other means of signal transduction has been listed for completeness. The advantages of $\mathrm{ZnO}$ nanocrystalline materials as platforms for high performance biosensors have been addressed. In a view of commercial perspectives, it is noteworthy that the $\mathrm{ZnO}$ nanomaterial preparation does not require high cost raw materials or equipment which leads to high expectations of successful commercial devices for many of the described biosensors.

\section{ACKNOWLEDGEMENTS}

This work was financially supported by grants from the Swedish Research Council (VR), Carl Tryggers foundation (CTS), VINNOVA and CeNano at Linköping University.

\section{REFERENCES}

1. J Wang, X Sun, A Wei, Y Lei, X Cai, C Li, Z Dong: Zinc oxide nanocomb biosensor for glucose detection. Appl Phys Lett 88, 233106 (2006)

2. E Gizeli: Design considerations for the acoustic waveguide biosensor. Smart Mater Struct 6, 700 (1997)

3. S A Kumar, S -M Chen: Nanostructured Zinc Oxide Particles in Chemically Modified Electrodes for Biosensor Applications. Anal Lett 41, 141 - 158 (2008)

4. Z L Wang: ZnO nanowire and nanobelt platform for nanotechnology. Materials Science and Engineering $R$ 64, 33-71 (2009)

5. B A Gregg: Excitonic solar cells. Journal of Physical Chemistry B 107, 4688-4698 (2003)

6. M Law, L E Greene, J C Johnson, R Saykally, P Yang: Nanowire dye-sensitized solar cells. Nat. Mat. 4, 455-459 (2005)

7 . I Gonzalez-Valls, M Lira-Cantu: Vertically-aligned nanostructures of ZnO for excitonic solar cells: a review. Energy Environment Science 2, 19-34 (2009)

8. www mixtl com

9. G S Tompa, S Sun, L G Provost, D Mentel, D Sugrim, P Chan, K Tong: Large Area Multi-Wafer MOCVD of Transparent and Conducting ZnO Films. Mater Res Soc Symp Proc 957, 0957-K09-05 (2007)

10 . V Khranovskyy, R Minikayev, S Trushkin, G Lashkarev, V Lazorenko, U Grossner, W Paszhkowicz, A Suchocki, B G Svensson, R Yakimova: Improvement of ZnO films properties by buffer layer application. J Cryst Growth 308, 93-98 (2007)

11. Z W Pan, Z R Dai, Z L Wang: Nanobelts of semiconducting oxides. Science 291, 1947-1949 (2001)

12. X Wang, J Song, P Li, J H Ryou, R D Dupuis, C J Summers, Z L Wang. J Am Chem Soc 127, 7920-7923 (2005) 
13. V Khranovskyy, I Tsiaoussis, G R Yazdi, L Hultman, R Yakimova: Heteroepitaxial ZnO nanohexagons on p-type SiC. J Cryst Growth 312, 327-332 (2010)

14. M Huang, Y Wu, H Feick, N Tran, E Weber, P Yang: Catalytic Growth of Zinc Oxide Nanowires by Vapor Transport. Adv Mater 13, 113-116 (2001)

15 . J Shi, Y Zhu, X Zhang, W R G Baeyens and A M García Campaña: Recent developments in nanomaterial optical sensors. Trends in Analytical Chemistry 23, 351 - 360 (2004)

16. Y C Kong, D P Yu, B Zhang, W Feng, S Q Feng: Ultraviolet-emitting ZnO nanowires synthesized by a physical vapor deposition approach. Appl Phys Lett 78, 407-410 (2001)

17. W I Park, D H Kim, S W Jung, G C Yi: Metalorganic vapor-phase epitaxial growth of vertically well-aligned ZnO nanorods. Appl Phys Lett 80, 4232-4235 (2002)

18. Z L Wang, R P Gao, Z W Pan, Z R Dai: Nano-scale Mechanics of Nanotubes, Nanowires and Nanobelts. Adv Eng Mater 3, 657-661 (2001)

19. Z R Dai, Z W Pan, Z L Wang: Ultra-long singlecrystalline nanoribbons of tin oxide. Solid State Communication 118, 351$354(2001)$

20. B S Kang, H -T Wang, L - C Tien, F Ren, B P Gila, D P Norton , C R Abernathy , J Lin, S J Pearton: Wide Bandgap Semiconductor Nanorod and Thin Film Gas Sensors. Sensors 6, 643-666 (2006)

21. S J Pearton, F Ren, Y -L Wang, B H Chu, K H Chen, C Y Chang, W Lim , J Lin , D P Norton: Recent advances in wide bandgap semiconductor biological and gas sensors. Progress in Materials Science 55, 1-59 (2010)

22. J Zhou, N Xu, Z L Wang: Dissolving Behavior and Stability of ZnO Wires in Biofluids: A Study on Biodegradability and Biocompatibility of ZnO Nanostructures Adv Mater 18, 2432-2435 (2006)

23 . Q H Li, Y X Liang, Q Wan,T H Wang: Oxygen sensing characteristics of individual ZnO nanowire transistors. Appl Phys Lett 85, 6389-6392 (2004)

24. H W Ryu, B S Park, S A Akbar, W S Lee, K J Hong, Y J Seo, D C Shin, J C Park, G P Choi: ZnO solrgel derived porous film for CO gas sensing. Sens Actuators B 96, 717-722 (2003)

25. H Gong, J Q Hu, J H Wang, C H Ong, R F Zhu: Nano-crystalline Cu-doped ZnO thin film gas sensor for CO. Sensors and Actuators B 115, 247-251 (2006)

26. M S Wagh, A L Patil, T Seth,D P Amalnerkar: Surface cupricated $\mathrm{SnO}_{2}-\mathrm{ZnO}$ thick films as a $\mathrm{H}_{2} \mathrm{~S}$ gas sensor. Mater Chem Phys 84, 228-233 (2004)

27. S P Singh, S K Arya, P Pandey, B D Malhotra, S Saha, K Sreenivas, V Gupta: Cholesterol biosensor based on rf sputtered zinc oxide nanoporous thin film. Appl Phys Lett 91, 063901 (2007)

28 . P R Solanki, A Kaushik, A A Ansari, B D Malhotra: Nanostructured zinc oxide platform for cholesterol sensor. Appl Phys Lett 94, 143901 (2009)

29 . J Eriksson, V Khranovskyy, F Söderlind, P -O Käll, R Yakimova, A -L Spetz: ZnO nanoparticles or ZnO films: A comparison of the gas sensing capabilities. Sensors and Actuators B 137, 94-102 (2009)

30 . J Watson: The tin oxide gas sensor and its application. Sensors and Actuators 5, 29-42 (1984)

31. X L Cheng, H Zhao, L H Huo, S Gao, J G Zhao: ZnO nanoparticle thin film: preparation, characterization and gas-sensing property. Sensors and Actuators B 102, 248-252 (2004)

32. V Khranovskyy, J Eriksson, A -L Spetz, R Yakimova, L Hultman: Effect of oxygen exposure on the electrical conductivity and gas sensitivity of nanostructured ZnO films. Thin Solid Films 517, 2073-2078 (2009)

33. Z Zhao, W Lei, X Zhang, B Wang and H Jiang: ZnO-Based Amperometric Enzyme Biosensors. Sensors 10, $1216-1231$ (2010) 
34. X Zhu, I Yuri, X Gan, I Suzuki, G Li: Electrochemical study of the effect of nano-zinc oxide on microperoxidase and its application to more sensitive hydrogen peroxide biosensor preparation. Biosensors Bioelectron 22, 1600-1604 (2007)

35. D Niwa, Y Yamada, T Homma, and T Osaka: Formation of Molecular Templates for Fabricating On-Chip Biosensing Devices. J Phys Chem B 108, 3240 - 3245 (2004)

36. F Heer, W Franks, A Blau, S Taschini, C Ziegler, A Hierlemann, and H Baltes: CMOS microelectrode array for the monitoring of electrogenic cells. Biosensors Bioelectron 20, 358 - 366 (2004)

37. H Kawarada, Y Araki, T Ogawa, and H Umezawa: Electrolyte-Solution-Gate FETs Using Diamond Surface for Biocompatible Ion Sensors. Phys Status Solidi A 185, 79 - 83 (2001)

38. W Yang, O Auciello, J E Butler, W Cai, J A Carlisle, J E Gerbi, D M Gruen, T Knickerbocker, T L Lasseter, J N Russell, Jr , L M Smith, and R J Hamers: DNA-modified nanocrystalline diamond thin-films as stable, biologically active substrates. Nat Mat $1,253-257(2002)$

39 . S Q Lud, M Steenackers, R Jordan, P Bruno, D M Gruen, P Feulner, J A Garrido, and M Stutzmann: Chemical grafting of biphenyl self-assembled monolayers on ultrananocrystalline diamond. J Am Chem Soc 128, 16884 - 16891 (2006)

40 . M Stutzmann, J A Garrido, M Eickhoff, and M S Brandt: Direct biofunctionalization of semiconductors: A survey. Phys Status Solidi A 203, 3424 - 3437 (2006)

41. P Ivanoff Reyes, Z Zhang, H Chen, Z Duan, J Zhong, G Saraf, Y Lu, O Taratula, E Galoppini, N Bousany: A ZnO nanostructure-based quartz crystal microbalance device for biochemical sensing. IEEE Sensor J 9, 1302 - 1307 (2009)

42 . O D Velev, B G Prevo and K H Bhatt: On-chip Manipulation of Free Droplets. Nature 426, 515 - 516 (2003); N Verplanck, Y Coffinier, V Thomy and R Boukherroub: Wettability Switching Techniques on Superhydrophobic Surfaces. Nanoscale Res Lett 2, 577 - 596 (2007)

43. V Zorba, E Stratakis, M Barberoglou, E Spanakis, P Tzanetakis, S H Anastasiadis and C Fotakis: Biomimetic Artificial Surfaces Quantitatively Reproduce the Water Repellency of a Lotus Leaf. Adv Mater 20, 4049 - 4054 (2008)

44. X Hong, X F Gao and L J Jiang: Application of Superhydrophobic Surface with High Adhesive Force in No Lost Transport of Superparamagnetic Microdroplet. Journal of the American Chemical Society 1291478 - 1479 (2007)

45. X Feng, M Jin, J Zhai, L Jiang, D Zhu, Reversible super-hydrophobicity to super-hydrophilicity transition of aligned ZnO nanorod films. Journal of the American Chemical Society 126, 62-63 (2004)

46. V Kekkonen, A Hakola, T Kajava, E Sahramo, J Malm, M Karppinen, and R H A Ras: Self-erasing and rewritable wettability patterns on $\mathrm{ZnO}$ thin films. Appl Phys Lett 97, 044102 (2010)

47. E L Papadopoulou, V Zorba, A Pagkozidis, M Barberoglou, E Stratakis, C Fotakis: Reversible wettability of ZnO nanostructured thin films prepared by PLD. Thin Solid Films 518, 1267 - 1270 (2009)

48 . J Lu, K Huang, X Chen, J Zhu, F Meng, X Song, Z Sun: Reversible wettability of nanostructured ZnO thin films by sol-gel method. Appl Surf Science 256, 4720 - 4723 (2010)

49 . N Tarwal, P S Patil: Superhydrophobic and transparent ZnO thin films synthesized by spray pyrolysis technique. App Surf Science 256, $7451-7456(2010)$

50. A B D Cassie, S Baxter : Wettability of porous surfaces. Trans Faraday Soc 40, 546 - 551 (1944)

51. J P Kar, S N Das, J H Choi, T I Lee, J M Myoung: Study of the morphological evolution of ZnO nanostructures on various sapphire substrates. App Surf Sci 256, 4995 - 4999 (2010)

52. S N Das, J H Choi, J P Kar, J M Myoung: Tunable and revercible surface wettability transition of vertically aligned ZnO nanorods arrays. App Surf Sci 255, 7319 - 7322 (2009)

53. X Zhu, Z Zhang, X Men, J Yang, X Xu: Fabrication of the intelligent superhydrophobic surface based on ZnO nanorods arrays with switchable adhesion property. Appl Surf Sci 256, 7619 - 7622 (2010) 
54 . J Xiong, S Das, B Shin, J Kar, J Choi, J Myoung: Biomimetic hierarchical ZnO structure with superhdrophobic and antireflective properties. J Colloid and Interface Sci 350, $344-347$ (2010)

55 . J Wang, J Chen, S Cao, S Xia, Y Zhu, G Xu: A fascile route to prepare ZnO super-hydrophobic surface with hierarchical structure. Material Chemistry and Physics 117, 183-186 (2009)

56 . V Khranovskyy, T Ekblad, R Yakimova and L Hultman: Size-dependent controllable wettability of ZnO nanostructures. Appl Surf Sci-submitted

57 . unpublished results (2010)

58. R D Sun, A Nakajima, A Fujishima, T Watanabe and K Hashimoto: Photoinduced Surface Wettability Conversion of ZnO and TiO2 Thin Films. J Phys Chem B 105, 1984 - 1990 (2001)

59. M Miyauchi, N Kieda, S Hishita, T Mitsuhashi, A Nakajima, T Watanabe and K Hashimoto: Reversible wettability control of $\mathrm{TiO}_{2}$ surface by light irradiation. Surf Sci 511, 401 - 407 (2002)

60 . S Hussain, L Braydich-Stolle, A Schrand, R Murdock, K Yu, D Mattie, J Schlager, and M Terrones: Toxicity Evaluation for Safe Use of Nanomaterials: Recent Achievements and Technical Challenges. Adv Mater 21, 1549-1559 (2009)

61 . A Nel, T Xia, L Mädler, N Li: Toxic potential of materials at the nanolevel. Science 311, 622-627 (2006)

62. A S Barnard: One-to-one comparison of sunscreen efficacy, aesthetics and potential nanotoxicity. Nat Nanotech 5, $271-274$ (2010)

63. T J Brunner, P Wick, P Manser, P Spohn, R N Grass, L K Limbach, A Bruinink, W J Stark: In vitro cytotoxicity of oxide nanoparticles: Comparison to asbestos, silica, and the effect of particle solubility. Environ Sci Technol 40, 4374 -4381 (2006)

64 . J Zhou, N Xu, Z L Wang: Dissolving Behavior and Stability of ZnO Wires in Biofluids: A Study on Biodegradability and Biocompatibility of ZnO Nanostructures. Adv Mater 18, 2432 - 2435 (2006)

65. N M Franklin, N J Rogers, S C Apte, G E Batley, G E Gadd, P S Casey: Comparative Toxicity of Nanoparticulate ZnO, Bulk $\mathrm{ZnO}$, and $\mathrm{ZnCl}_{2}$ to a Freshwater Microalga (Pseudokirchneriella subcapitata): The Importance of Particle Solubility. Env Sc \& Tech 41, 8484 - 8490 (2007)

66. W Stumm, J Morgan: Chemical Equilibria and Rates in Natural Waters J Aquatic Chemistry 3rd ed ; Wiley-Interscience: New York, 1995

67. Z Yang,C Xie: $\mathrm{Zn}^{2+}$ release from zinc and zinc oxide particles in simulated uterine solution. Colloids Surf B 47 140-145 (2006)

68. F Roelofs, W Vogelsberger: Dissolution kinetics of synthetic amorphous silica in biological-like media and its theoretical description. J Phys Chem B 108 11308-11316 (2004)

69. Stefan Erhler, Diploma Thesis: Doped ZnO nanoparticles for gas sensing, 2007

70. Www znordic com

71. unpublished results

72 . R Brayner, S A Dahoumane, C Yepremian, C Djediat, M Meyer, A Coute, and F Fievet: ZnO Nanoparticles: Synthesis, Characterization, and Ecotoxicological Studies. Langmuir 26, 6522 - 6528 (2010)

73 . S Ostrovsky, G Kazimirsky, A Gedanken and C Brodie: Selective cytotoxic effect of ZnO nanoparticles on glioma cells. Nano Res 2, $882-890$ (2009)

74. V Khranovskyy, I Tsiaoussis, L A Larsson, P O Holtz, R Yakimova: Nanointegration of ZnO with Si and SiC. Phys B 404, $4359-4363(2009)$

75. A Dierstein, H Natter, F Meyer, H Stephan, C Kropf, R Hempelmann: Electrochemical deposition under oxidizing conditions (EDOC): a new synthesis for nanocrystalline metal oxides. Scr Mater 44, 2209-2212 (2001) 
76. G S Huang, X L Wu,_Y C Cheng, J C Shen, A P Huang, P K Chu: Fabrication and characterization of anodic ZnO nanoparticles. Appl Phys A 86, 463-467 (2007)

77 . L Selegard, V Khranovskyy, F Söderlind, C Vahlberg, M Ahrén, PO Käll, R Yakimova, K Uvdal: Biotinylation of ZnO nanoparticles and thin films: a two-step surface functionalization study. ACS Appl Mater Interfaces 22128 - 2135 (2010)

78. Y -F Li, Z -M Liu, Y -L Liu, Y -H Yang, G -L Shen, R -Q Yu: A mediator-free phenol biosensor based on immobilizing tyrosinase to $\mathrm{ZnO}$ nanoparticles. Analytical Biochemistry 349, 33-40 (2006)

79. A Moballegh, H Shahverdi, R Aghababazadeh, A Mirhabibi: ZnO nanoparticles obtained by mechanochemical technique and their optical properties. Surface Science 601, 2850 - 2854 (2007)

80 . X Ren, D Chen, X Meng, F Tang, X Hou, D Han, L Zhang: Zinc oxide nanoparticles/glucose oxidase photoelectrochemical system for the fabrication of biosensor. Journal of Colloid and Interface Science 334, 183-187 (2009)

81. S S Habib: Highly crystalline ZnO nanoparticles. Int J Nanoparticles 2, 30 - 42 (2009)

82. T Canh, N V Tuyen, N N Long: Influence of solvents on the growth of zinc oxide nanoparticles fabricated by microwave irradiation. VNU Journal of Science, Mathematics - Physics 25, 71-76 (2009)

83. V Khranovskyy, A Ulyashin, G Lashkarev, B G Svensson, R Yakimova: Morphology, electrical and optical properties of undoped $\mathrm{ZnO}$ layers deposited on silicon substrates by PEMOCVD. Thin Solid Films 516, 1396-1400 (2008)

84 . S P Singh, S K Arya, P Pandey, B D Malhotra, S Saha, K Sreenivas, V Gupta: Cholesterol biosensor based on rf sputtered zinc oxide nanoporous thin film. Appl Phys Lett 91, 063901 (2007)

85 . P R Solanki, A Kaushik, A A Ansari, and B D Malhotra: Nanostructured zinc oxide platform for cholesterol sensor. Appl Phys Lett 94, 143901 (2009)

86. Y Q Miao, S W Tan: Amperometric hydrogen peroxide biosensor based on immobilization of peroxidase in chitosan matrix crosslinked with glutaraldehyde. Analyst 125, 1591 - 159 (2000)

87. H Okuma, E Watanabe: Flow system for fish freshness determination based on double multi-enzyme reactor electrodes. Biosens Bioelectron 17, 367 - 372 (2002)

88 . D Segets, J Gradl, R Klupp-Taylor, V Vassilev, W Peukert: Analysis of optical absorbance spectra for the determination of $\mathrm{ZnO}$ nanoparticle size distribution, solubility, and surface energy. ACS Nano 3, 1703-1710 (2009)

89 . N R Jana, H Yu, E Ali, Y Zheng, J Y Ying,: Controlled photostability of luminescent nanocrystalline ZnO solution for selective detection of aldehydes. Chem Commun 14, 1406-1408 (2007)

90 . S T Selvan, T T Y Tan, D K Yi, N R Jana: Functional and Multifunctional Nanoparticles for Bioimaging and Biosensing. Langmuir 26, 11631 - 11641 (2009)

91. A Lenz, L Selegard, F Soderlind, A Larsson, P O Holtz, K Uvdal, L Ojamae, P O Kall: ZnO Nanoparticles Functionalized with Organic Acids: An Experimental and Quantum-Chemical Study. J Phys Chem C 113, 17332- 17341 (2009)

92. Y Gong, T Andelman, G F Neumark, S O’Brien, I L Kuskovsky: Origin of defect-related green emission from ZnO nanoparticles: effect of surface modification. Nanoscale Res Lett 2, 297 - 302 (2007)

93 . N S Norberg, D R Gamelin: Influence of Surface Modification on the Luminescence of Colloidal ZnO Nanocrystals. J Phys Chem B 109, 20810-20816 (2005)

94. V Khranovskyy, U Grossner, V Lasorenko, G Lashkarev, B G Svensson, R Yakimova: Study of annealing Influence on the electrical and morphological properties of ZnO:Ga films. Phys Stat Sol (c) 3, 780-784 (2006)

95 . F Xu, Y Lu, Y Xie, Y Liu: Large-scale electrodeposition of $\mathrm{ZnO}$ thin films with novel petal-like architectures. Vacuum 83, 360-365 (2008)

96. J H Li, b, D Z Shen, J Y Zhang, D X Zhao, B S Li, Y M Lu, Y C Liu and X W Fan: Magnetism origin of Mn-doped ZnO nanoclusters. J Magn Mater 302, 118 - 121 (2006) 
97. Z K Tang, G K L Wong, P Yu, M Kawasaki, A Ohtomo, H Koinuma, Y Segawa: Room-temperature ultraviolet laser emission from self-assembled ZnO microcrystallite thin films. Appl Phys Lett 72, 3270 (1998)

98. P Sharma, A Gupta, K Rao, F J Owens, R Sharma, R Ahuja, J O Guillen, B Johansson, G A Gehring: Ferromagnetism above room temperature in bulk and transparent thin films of Mn-doped ZnO. Nature 2, 673 - 677 (2003)

99. K J Sharda, S Chawla: Synthesis of Mn doped ZnO nanoparticles with biocompatible capping. Applied Surface Science 256, 2630-2635 (2010)

100 . P W Tasker: The stability of ionic crystal surfaces. Journal of Physics C: Solid State Physics 12, 4977-4984 (1979)

101. B J Coppa, C C Fulton, P J Hartlieb: In situ cleaning and characterization of oxygen- and zinc-terminated, n-type, $\mathrm{ZnO}\{0001\}$ surfaces. Journal of Applied Physics 95, 5856-5864 (2004)

102 . unpublished data (2010)

103 . E P Plueddemann: Silane adhesion promoters in coatings. Prog Org Coat 11, 297-308 (1983)

104 . T Van Schaftinghen, C Le Pen, H Terryn, F Hörzenberger: Investigation of the barrier properties of silanes on cold rolled steel. Electrochim Acta 49, 2997-3004 (2004)

105 . C Vahlberg, G R Yazdi, R M Jr Petoral, V Khranovskyy, M Syväjärvi, K Uvdal, A Lloyd Spetz, R Yakimova: Surface engineering of functional materials for biosensor. Proc IEEE Sens 504-507 (2005)

106 . D G Castner, K Hinds and D W Grainger: X-ray Photoelectron Spectroscopy Sulfur 2p Study of Organic Thiol and Disulfide Binding Interactions with Gold Surfaces. Langmuir 12, 5083-5086 (1996)

107 . R M Petoral Jr,, G R Yazdi, A Lloyd Spetz, R Yakimova, K Uvdal: Organosilane-functionalized wide bandgap semiconductor surfaces. Appl Phys Lett 90, 223904 (2007)

108 . R Yakimova, G Steinoff, R M Petoral Jr, C Vahlberg, V Khranovskyy, G R Yazdi, K Uvdal, A Lloyd Spetz: Novel material concepts of transducers for chemical and biosensors. Biosens Bioelectron 22, 2780-2785 (2007)

109 . N Pesika, Z Hu, K Stebe, and P C Searson: Quenching of growth of ZnO nanoparticles by adsorption of octanethiol. J Phys Chem B 106, 6985 (2002)

110 . G Cicero, G Galli, and A Catellani: Interaction of Water Molecules with SiC (001) Surfaces. J Phys Chem B 108,16518 (2004)

111. P W Sadik, S J Pearton, and D P Norton: Functionalizing Zn- and O-terminated ZnO with thiols. J Appl Phys 101, 104514 (2007)

112 . N R Jana, C Earhart, J Y Ying: Synthesis of Water-Soluble and Functionalized Nanoparticles by Silica Coating. Chem Mater 19, 5074-5082 (2007)

113. C Corso, A Dickherber, W Hunt: An investigations of antibody immobilization methods employing organosilanes on planar $\mathrm{ZnO}$ surfaces for biosensor applications. Biosensors and Bioelectonics 24, $805-811$ (2008)

114. S A Kumar, S-M Chen: Nanostructured Zinc Oxide Particles in Chemically Modified Electrodes for Biosenor Applications. Analytical Letters 41:2, 141 - 158 (2008)

115. Y Q Fu, J K Luo, X Y Du, A J. Flewitt, Y. Li, G H Markx, A J Walton, W I Milne: Recent developments on ZnO films for acoustic wave based bio-sensing and microfluidic applications: a review. Sensors and Actuators B:Chemical 143, $606-619$ (2009)

116. Z Zhao, W Lei, X Zhang, B Wang, H Jiang: ZnO-Based Amperometric Enzyme Biosensors: Review. Sensors 10, 12161231 (2010)

117. M Vellekoop: Acoustic wave sensors and their technology. Ultrasonics 36, 7-14 (1998)

118. S Shiokawa, J Kondohl: Surface Acoustic Wave Sensors. Jpn J Appl Phys 43 2799-2802 (2004) 
119. G Cote, R Lec, M Pishko: Emerging biomedical sensing technologies and their applications. Sensors Journal IEEE 3, 251$266(2003)$

120. F Teles, L Fonseca: Trends in DNA biosensors. Talanta 77, 606-623 (2008)

121. L Kuznetsova, W Coakley: Applications of ultrasound streaming and radiation force in biosensors. Biosensors and Bioelectronics 22, 1567-1577 (2007)

122. K Marx: Quartz Crystal Microbalance: A Useful Tool for Studying Thin Polymer Films and Complex Biomolecular Systems at the Solution-Surface Interface. Biomacromolecules 4, 1099-1120 (2003)

123. G Kovacs, A Venema: Theoretical comparison of sensitivities of acoustic shear wave modes for (bio)chemical sensing in liquids. Appl Phys Lett 61, 639 (1992)

124. L Lee, Y Fu, S Maeng, J Luo, N Park, S Kim, M Jung and W Milne: ZnO surface acoustic wave biosensor. International Electron Devices Meeting Washington DC, December 10-12 (2007).

125. C Wood, S Evens, J Cumingham, R O'Rorke, C Walti, A Davies: Alignment of particles in microfluidic systems using standing surface acoustic wave. Appl Phys Lett 92, 044104 (2008)

126. S Chu, W Water, J Liaw: An investigation of the dependence of $\mathrm{ZnO}$ film on the sensitivity of Love mode sensor in $\mathrm{ZnO/quartz} \mathrm{structure.} \mathrm{Ultrasonics} \mathrm{41,} 133$ (2003)

127. S Jian, S Chu, T Huang, W Water: Study of preferred orientation of zinc oxide films on the $64^{\circ} \mathrm{LiNbO}_{3}$ substrates and their applications as liquid sensors. J Vac Sci Technol A22, 2424 - 2430 (2004)

128. S Krishnamoorthy, A Iliadis: Development of high frequency $\mathrm{ZnO} / \mathrm{SiO} 2 / \mathrm{Si}$ Love mode surface acoustic wave devices. Solid-State Electron 50, 1113 (2006)

129. D Powell, K Kalatair-Zadeh, W Wlodaiski: Numerical calculation of SAW sensitivity: application to $\mathrm{ZnO} / \mathrm{LiTaO}_{3}$ transducers. Sens. Actuat. A 115, 456-461 (2004)

130. J Du, G Harding: A multilayer structure for Love-mode acoustic sensors. Sens. Actuat. A 65, 152-159 (1998)

131. P Muralt, N Ledermann and J Baborowski, A Barzegar, S Gentil, B Belgacem, S Petitgrand, A Bosseboeuf, N Setter: Piezoelectric micromachined ultrasonic transducers based on PZT thin films. IEEE Trans. Ultrasonic Ferroelectr. Freq. Control 52, 2276 (2005)

132. R White: Introductory Lecture Acoustic interactions from Faraday's crispations to MEMS. Faraday Discuss. 107, 1 (1997)

133. I Huang, M Lee: Development of a FPW allergy biosensor for human IgE detection by MEMS and cystamine-based SAM technologies. Sens. Actuat. B 132, 340-348 (2008)

134. R Ruby: Review and Comparison of Bulk Acoustic Wave FBAR, SMR Technology. IEEE Ultrasonics Symp Proc 1-6, 1029-1040 (2007)

135. G. Wingqvist: AlN-based sputter-deposited shear mode thin film bulk acoustic resonator (FBAR) for biosensor applications - A review. Surface \& Coatings Technology 205, 1279-1286 (2010)

136. R Gabl, H Feucht, H Zeininger, G Eckstein, M Schreter, R Primig, D Pitzer, W Wersing: First results on label-free detection of DNA and protein molecules using a novel integrated sensor technology based on gravimetric detection principles. Biosens. Bioelectron. 19, 615 (2004)

137. R Lin, Y Chen, W Chang, C Cheng, K Koo: Highly sensitive mass sensor using film bulk acoustic resonator. Sens. Actuat. A $147,425-429(2008)$

138. A Dorfman, N Kumar, J Hahm: Nanoscale ZnO-Enhanced Fluorescence Detection of Protein Interactions. Adv Mater 18, 2685 (2006)

139. J Wang, K Lakin: c axis inclined ZnO piezoelectric shear wave films. Appl Phys Lett 42, 352 (1983) 
140. J-B Lee, M-H Lee, C-K Park, J-S Park: Effects of lattice mismatches in ZnO/substrate structures on the orientations of ZnO films and characteristics of SAW devices. Thin Solid Films 447 -448, 296-301 (2004)

141. V Khranovskyy, U Grössner, V Lazorenko, G Lashkarev, B G Svensson, R Yakimova: Conductivity increase of ZnO:Ga films by rapid thermal annealing. Superlattices and Microstructures 42, 379 - 386 (2007)

142. M Link, M Schreiter, J Weber, R Gabl, D Pitzer, R Primig, W Wersing, M Assouar, O Elmazria: C -axis inclined ZnO films for shear-wave transducers deposited by reactive sputtering using an additional blind. J Vac Sci Technol A 24, 218-222 (2006)

143. Y. Miyamoto, T. Yangaitani, Y. Watanabe: Effect of sputtering geometry on (1120) textured ZnO piezofilm. Acoust Sci Technol 27, 53 - 55 (2006)

144. V Khranovskyy, U Grossner, V Lazorenko, G Lashkarev, B G Svensson, R Yakimova: PEMOCVD of ZnO thin films, doped by Ga and some of their properties. Superlattices and Microstructures 39, 275-281 (2007)

145. V Khranovskyy, U Grossner, O Nilsen, V Lazorenko, G V Lashkarev, B G Svensson, R Yakimova, Structural and morphological properties of ZnO:Ga thin films. Thin Solid Films 515 472-476 (2006)

146. J Weber, W Albers, J Tuppurainen, M Link, R Gabl, W Wersing, M Schreiter: Shear mode FBARs as highly sensitive liquid biosensors. Sens Actuat A 128, 84 - 88 (2006)

147. M Link, M Schreiter, J Weber, R Primig, D Pitzer, R Gabl: Solidly mounted ZnO shear mode film bulk acoustic resonators for sensing applications in liquids. IEEE Trans Ultrasonic Ferroelectr Freq Control 53, 492-496 (2006)

148. S Pearton, D Norton, K Ip, Y. Heo, T Steiner: Recent progress in processing and properties of ZnO. Prog Mater Sci 50293 (2005)

149. F Zhang, X Wang, S Ai, Z Sun, Q Wa, Z Zhu, Y Xian, L Jin, K Yamamoto: Immobilization of uricase on ZnO nanorods for a reagentless uric acid biosensor. Anal Chim Acta 519, 155 - 160 (2004)

150. Y Lei, X Yan, J Zhao, X Liu, Yu Song, N Luo, Y Zhang: Improved glucose electrochemical biosensors by appropriate immobilization of nano-ZnO. Colloids and Surfaces B: Biointerfaces 82, 168 - 172 (2011)

151. X Du, Y Fu, S Tan, J Luo, A Flewitt, D Lee, S Maeng, S Kim, Y Choi, N Park, J Park, W Milne: Microfluidic pumps employing surface acoustic waves generated in ZnO thin films. J Appl Phys 105, 024508 (2009)

152. S Krishnamoorthy, T Bei, E Zoumakis, G. Chrousos, A Iliadis> Morphological and binding properties of interleukin-6 on thin $\mathrm{ZnO}$ filmsgrown on (100) silicon substrates for biosensor applications. Biosensors and Bioelectronis 22707 - 714 (2006)

153. S. Khrishnamoorthy, A. Iliadis, $\mathrm{T}$ Bei, G Chrousos: An interleukin- $6 \mathrm{ZnO} / \mathrm{SiO}_{2} / \mathrm{Si}$ surface acoustic wave biosensor. Biosensor and Bioelectronics 24, 313- 318 (2008)

154. S Knudsen, J Lee, A Ellington,C Savran: Ribozyme-Mediated Signal Augmentation on a Mass-Sensitive Biosensor. J Am Chem Soc 128, 15936-15937 (2006)

155. S Saha, V Gupta, K Sreenivas, H Tan, C Jagasish: Third generation biosensing matrix based on Fe-implanted ZnO thin films. Appl Phys Lett 97, 133704 (2010)

156. D Pradhan, F Niroui, K Leung: High-Performance, Flexible Enzymatic Glucose Biosensor Based on ZnO Nanowires Supported on a Gold-Coated Polyester Substrate. ACS Applied Materials and Interfaces 2, 2409 - 2412 (2010)

157. Z Zhao, X Chen, B Tay, J Chen, Z Han, K Khor: A novel amperometric biosensor based on ZnO:Co nanoclusters for biosensing glucose. Biosensors and Bioelectronics 23, 135-139 (2007)

Key Words: Zinc oxide, nanocrystals, nanoparticles, biofunctionalization, organosilanes

Send correspondence to: Rositza Yakimova, Department of Physics, Chemistry and Biology (IFM), Linkoping University, SE58183 Linkoping, Sweden Tel: 46-13-282528, Fax: 46-13-137568 E-mail: roy@ifm.liu.se 
Table 1. The content of the solution after immersing the $\mathrm{ZnO}$ samples (after 7 days, $36{ }^{\circ} \mathrm{C}$ )

\begin{tabular}{|l|l|l|l|l|l|l|l|}
\hline \multirow{2}{*}{ Type of the material } & Elements, mass \% & \multicolumn{3}{l|}{} \\
\cline { 2 - 8 } & $\mathbf{C a}$ & $\mathbf{F e}$ & $\mathbf{Z n}$ & $\mathbf{B r}$ & $\mathbf{A g}$ & $\mathbf{S i}$ & $\mathbf{S}$ \\
\hline ZnO single crystal & 0.003 & 0.002 & - & - & 0.001 & 0.001 & 0.001 \\
\hline $\begin{array}{l}\text { ZnO nanoparticles } \\
\text { (as-grown) }\end{array}$ & 0.002 & 0.002 & 0.001 & 0.026 & 0.005 & 0.003 & 0.002 \\
\hline ZnO nanoparticles (rinsed) & 0.002 & 0.004 & 0.002 & 0.001 & 0.002 & 0.004 & 0.001 \\
\hline
\end{tabular}

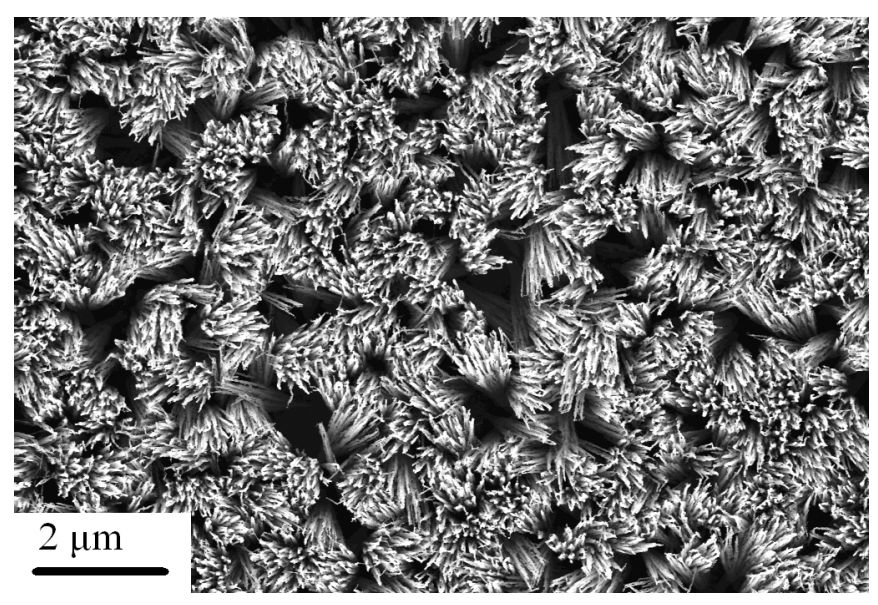

Figure 1. SEM image of $\mathrm{ZnO}$ nanosheafs.

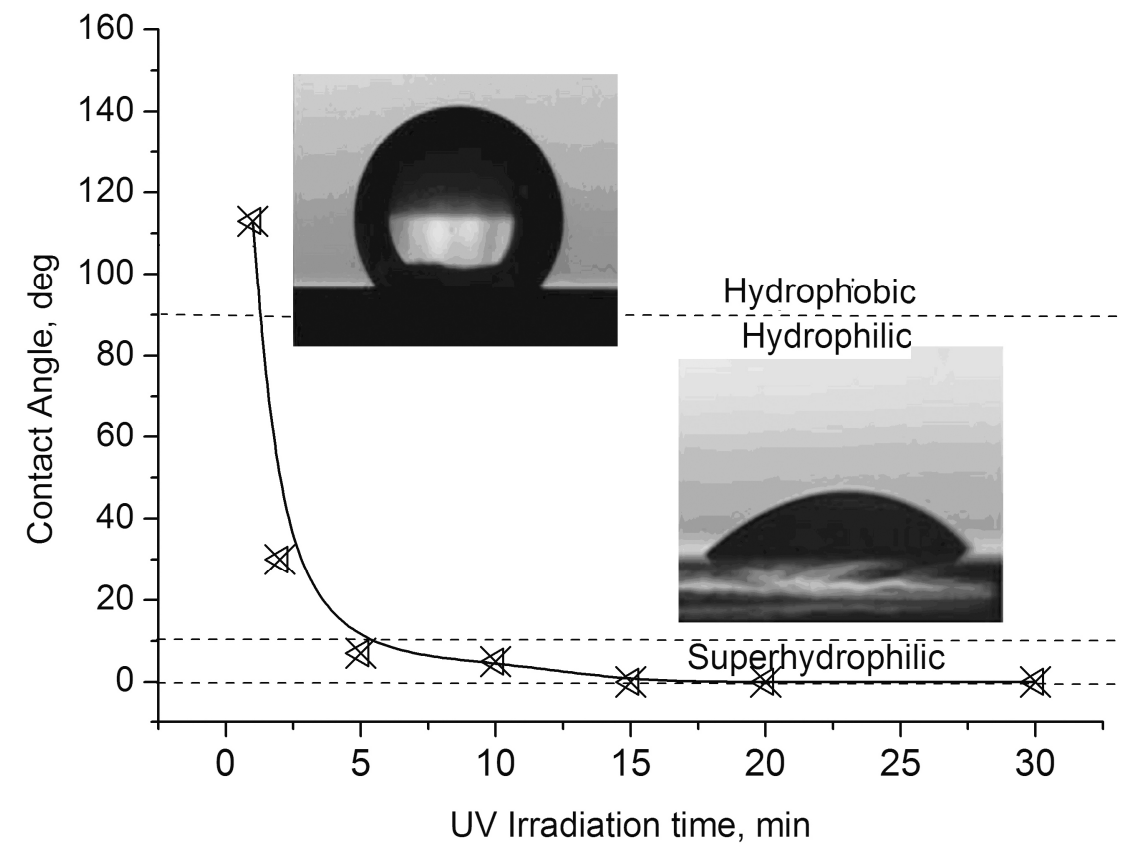

Figure 2. Contact angle time dependence under the UV radiation of $\mathrm{ZnO}$ nanostructures (nanosheafs). The respective transition regions from hydrophobic to hydrophilic and superhydrophilic are demarked. The insets represent the contact angle images before (top left) and after the 5 minutes of UV irradiation (bottom right) respectively. 

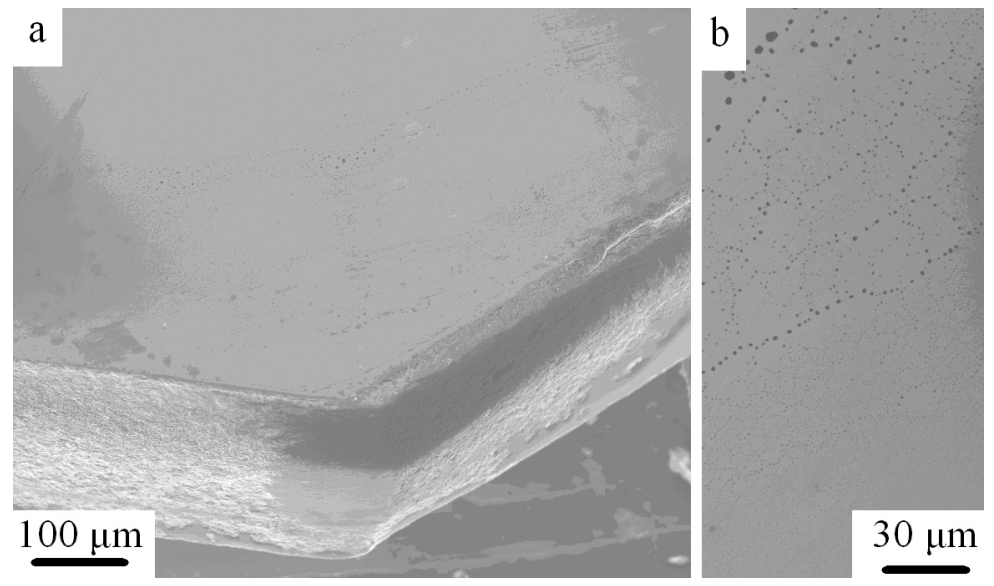

Figure 3. SEM images of bulk $\mathrm{ZnO}$ : a - crystal side view; $\mathrm{b}$ - surface of the crystal.

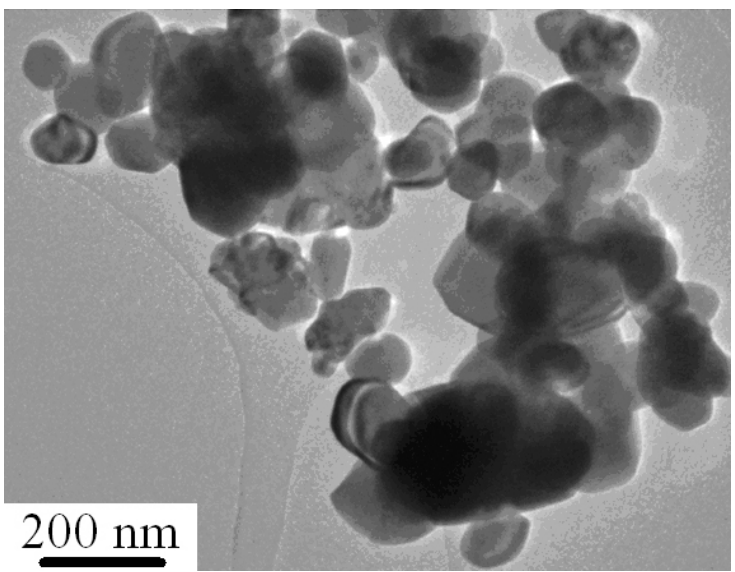

Figure 4. TEM image of the as grown $\mathrm{ZnO}$ nanoparticles (redrawn from (69)).

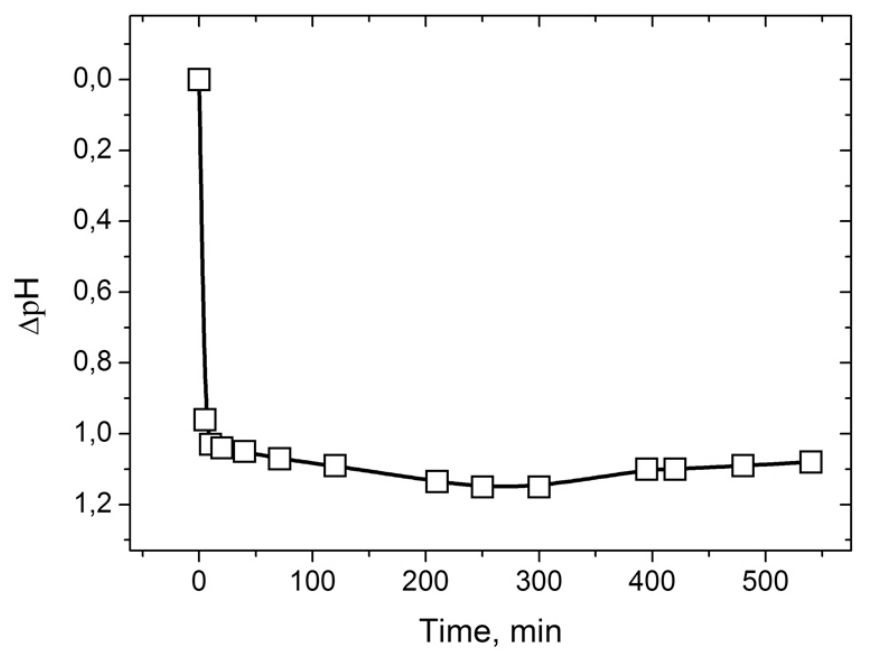

Figure 5. The $\mathrm{pH}$ change of the solution after plunging of the as-grown $\mathrm{ZnO}$ nanoparticles (redrawn from (71)). 

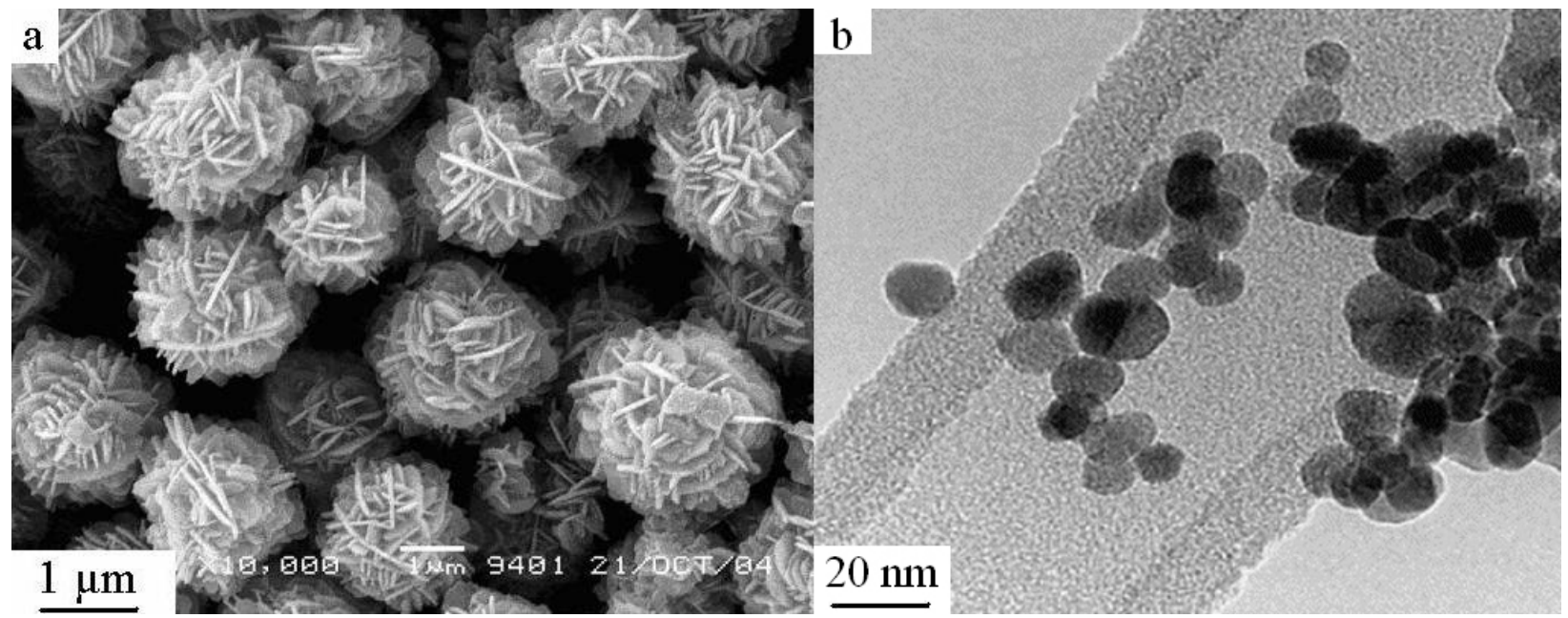

Figure 6. SEM (a) and TEM (b) images of as-synthesized ZnO nanoparticles. Reprinted from Y -F Li, Z -M Liu, Y -L Liu, Y -H Yang, G -L Shen, R -Q Yu: A mediator-free phenol biosensor based on immobilizing tyrosinase to ZnO nanoparticles. Analytical Biochemistry 349, 33-40 (2006) and A Moballegh, H Shahverdi, R Aghababazadeh, A Mirhabibi: ZnO nanoparticles obtained by mechanochemical technique and their optical properties. Surface Science 601, 2850 - 2854 (2007) respectively, with permission from Elsevier.

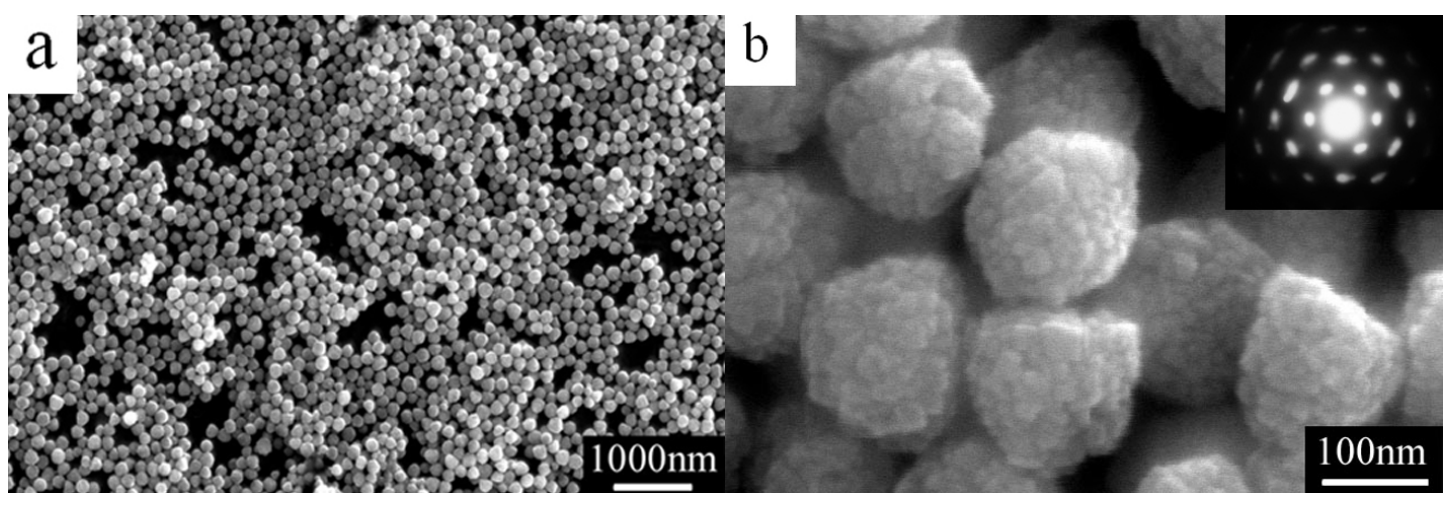

Figure 7. (a) Typical SEM image of the ZnO nanoparticles; (b) high-magnification SEM image of the ZnO nanoparticles. The inset shows the selected area electron diffraction (SAED) pattern obtained by focusing the electron beam on a $\mathrm{ZnO}$ nanoparticles. Reprinted from X Ren, D Chen, X Meng, F Tang, X Hou, D Han, L Zhang: Zinc oxide nanoparticles/glucose oxidase photoelectrochemical system for the fabrication of biosensor. Journal of Colloid and Interface Science 334, 183-187 (2009) with permission from Elsevier.

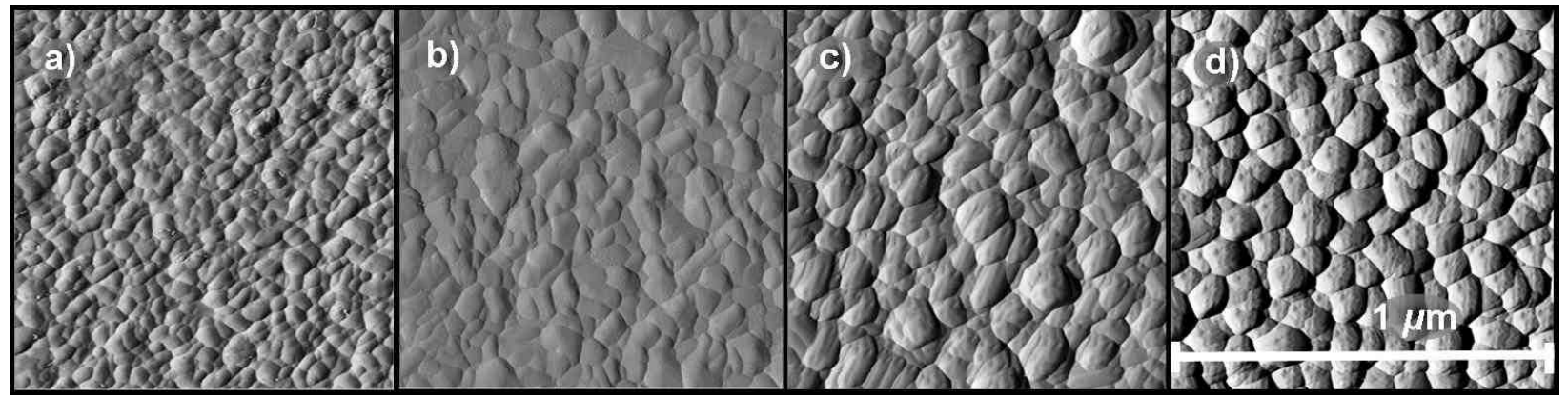

Figure 8. AFM images showing the grain evolution in $\mathrm{ZnO}$ films, annealed for 30 minutes in air in a temperature range of ( 300 $600{ }^{\circ} \mathrm{C}$ a) as-grown film, b) $300{ }^{\circ} \mathrm{C}$, c) $500{ }^{\circ} \mathrm{C}$ and d) $600{ }^{\circ} \mathrm{C}$. The image size is $1 \mathrm{x} 1 \mu \mathrm{m}$ for all four images. Height amplitude (Zscale for all images, redrawn from (77)). 


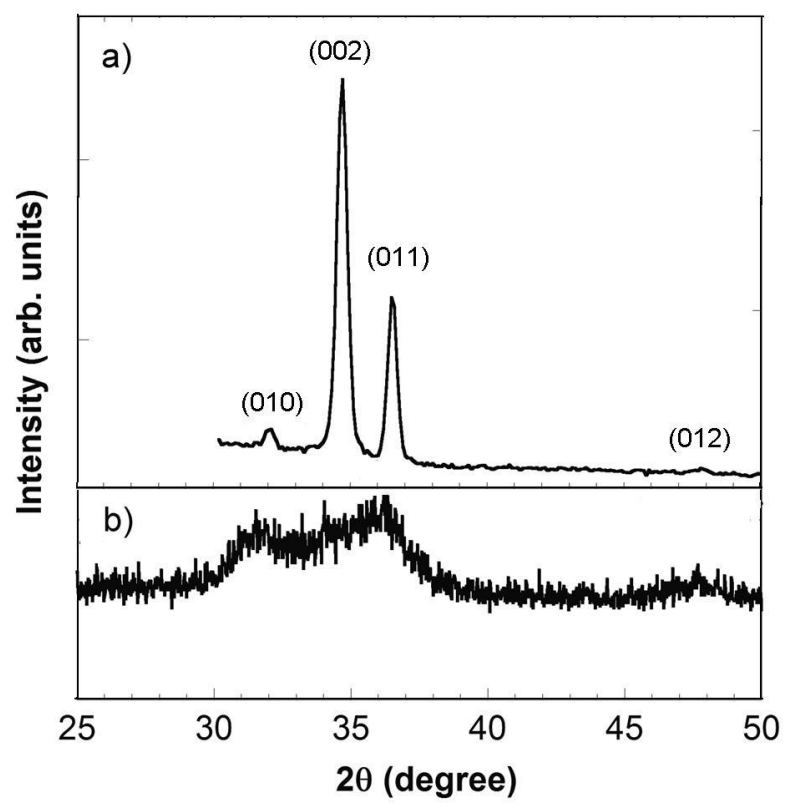

Figure 9. XRD spectrum of a) as-grown $\mathrm{ZnO}$ films and b) tetrabutylammonium bromide (TBAB) capped as-synthesized $\mathrm{ZnO}$ nanoparticles (redrawn from (77))

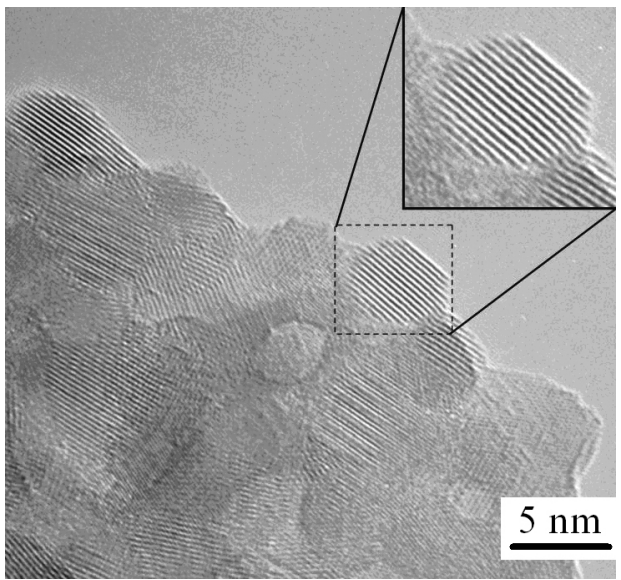

Figure 10. TEM image of as synthesized TBAB capped $\mathrm{ZnO}$ nanoparticles. An enlarged particle is shown as an inset (redrawn from (77))

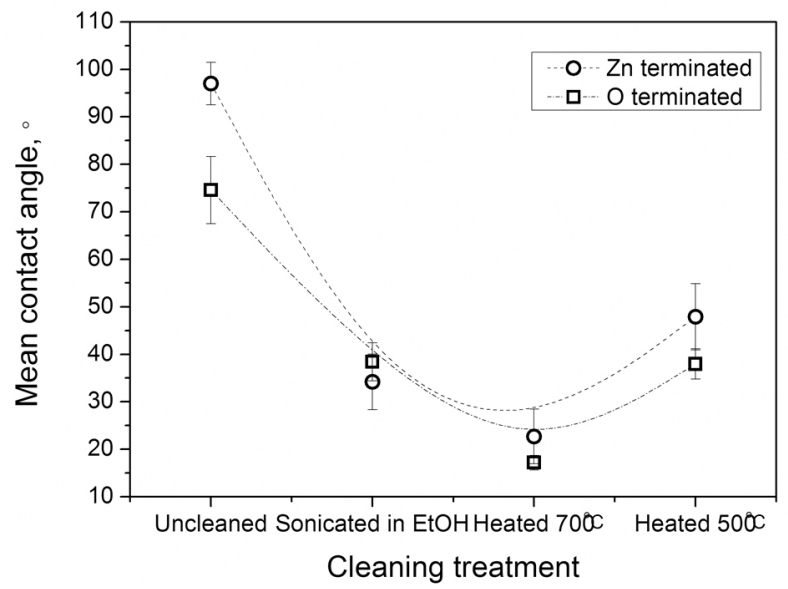

Figure 11. Contact angle dependence on the $\mathrm{ZnO}$ surface treatment procedure for $\mathrm{Zn}$ - and O-terminated faces of $\mathrm{ZnO}$ bulk crystal (redrawn from (102)). The lines are guide for eyes. 


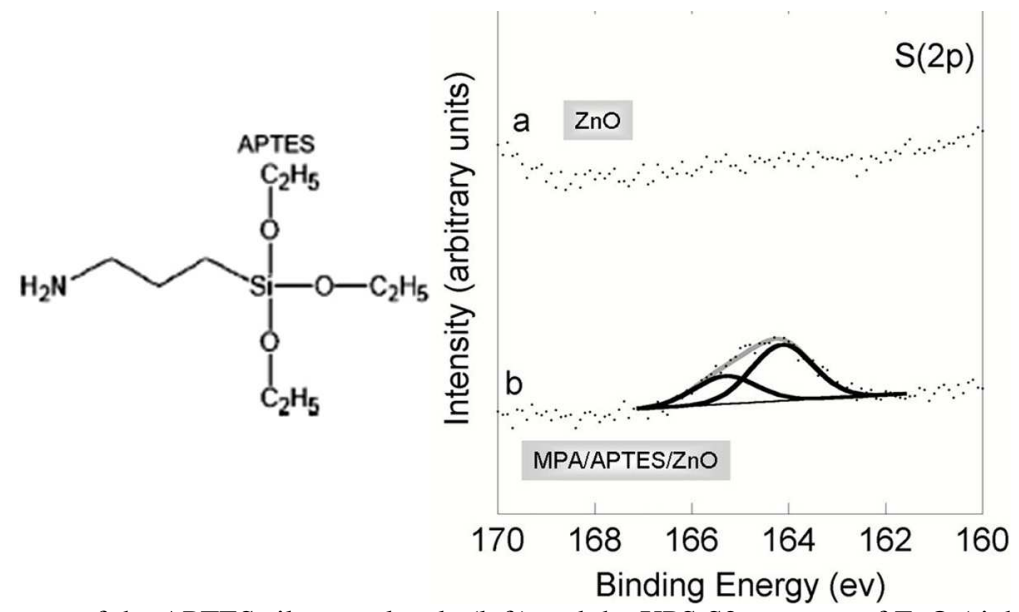

Figure 12. Chemical structure of the APTES silane molecule (left) and the XPS S2p spectra of ZnO (right) a) before and b) after biofunctionalization (redrawn from (105))
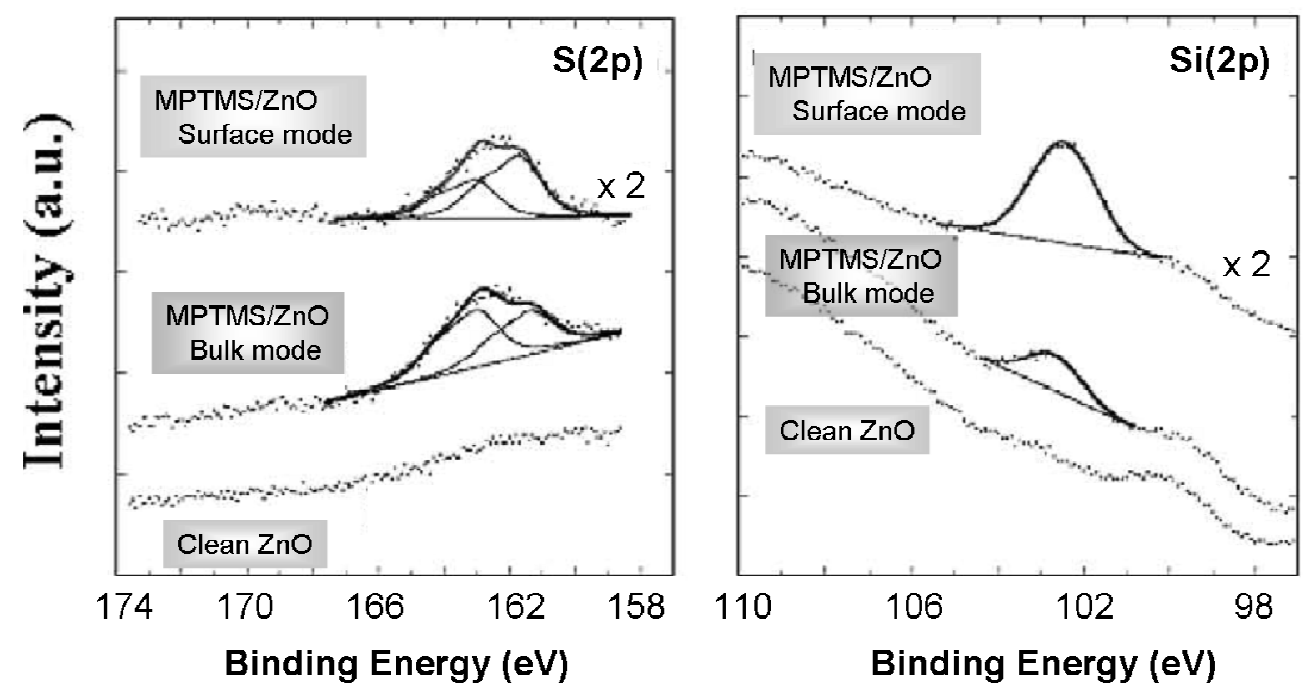

Figure 13. Core level XPS spectra for S $2 p$ (left) and Si $2 p$ (right) of clean and MPTS fuctionalized ZnO (redrawn from (107)). Spectra are show for comparison.

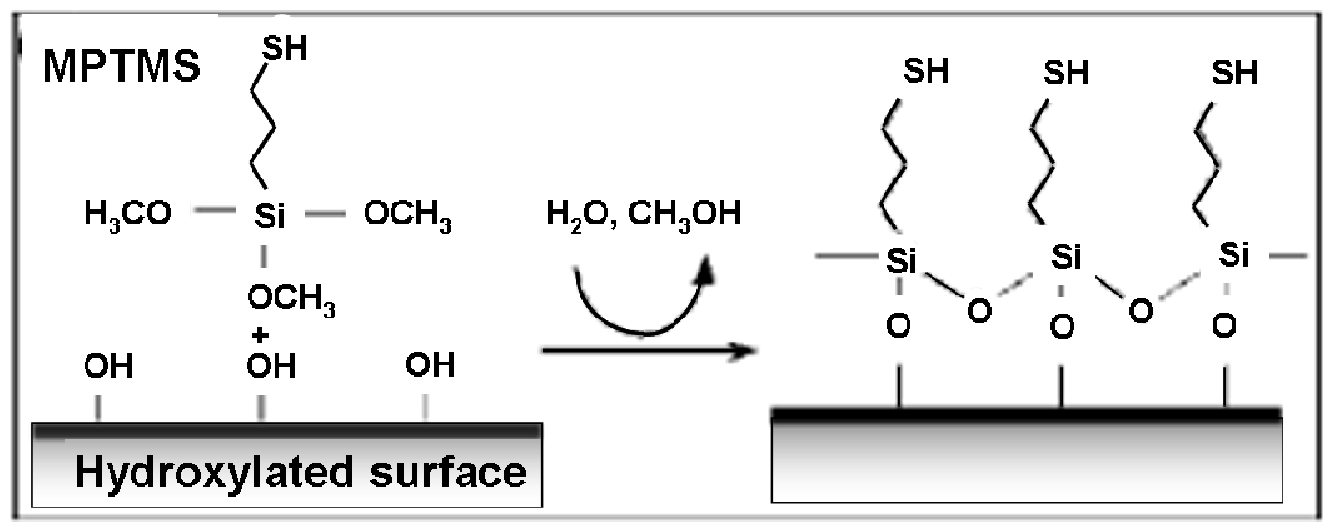

Figure 14. Schematic drawing of procedure for the MPTS reaction on hydroxylated surfaces (redrawn from (107)). 


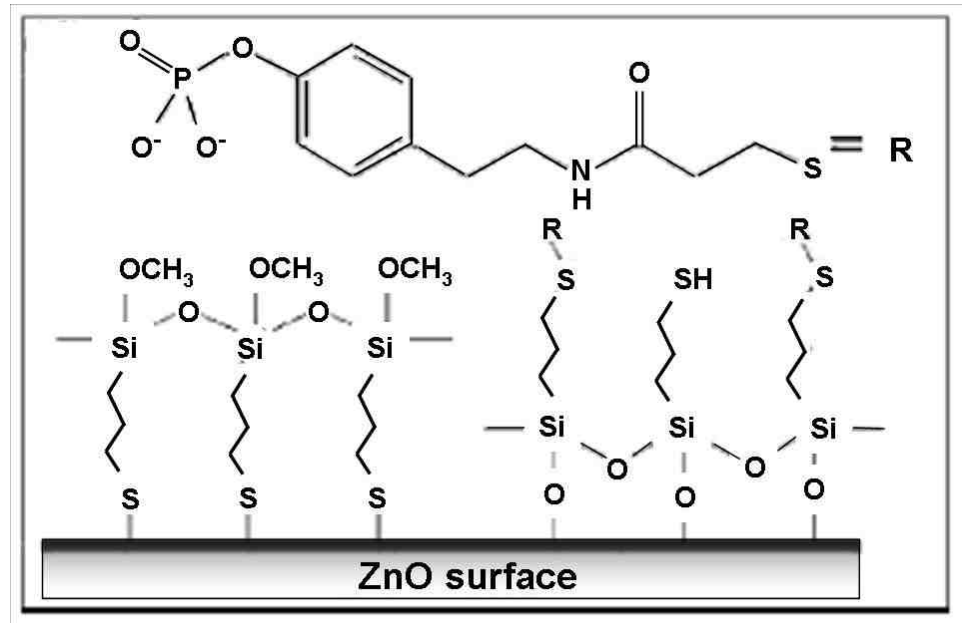

Figure 15. Schematic drawing of the functionalization procedure, including in disulfide bridge formation. In this case phosphotyrosine analog (pTyr-PT) is linked to MPTS-functionalized ZnO surface (redrawn from (107)).

Treated
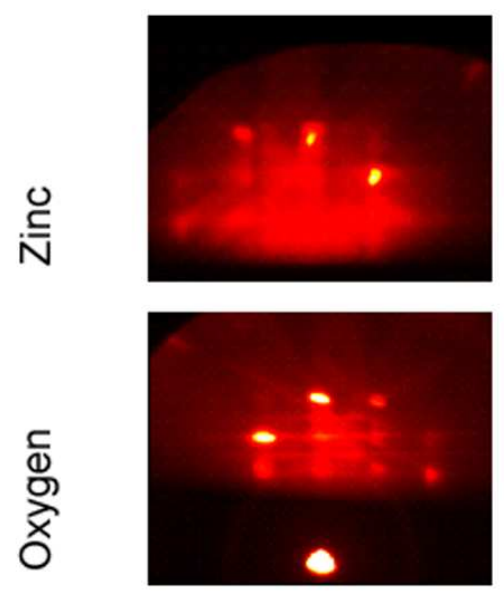

Untreated
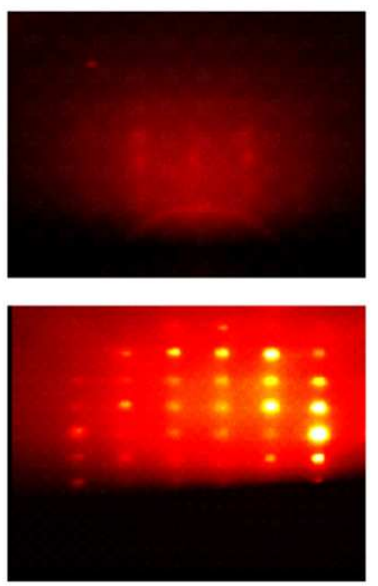

Figure 16. RHEED patterns for Zn-terminated and O-terminated $\mathrm{ZnO}$ surfaces after $250{ }^{\circ} \mathrm{C}$ temperature treatment. Reprinted with permission from (P W Sadik, S J Pearton, and D P Norton: Functionalizing Zn- and O-terminated ZnO with thiols. J Appl Phys 101, 104514 (2007)). Copyright 2007, American Institute of Physics.

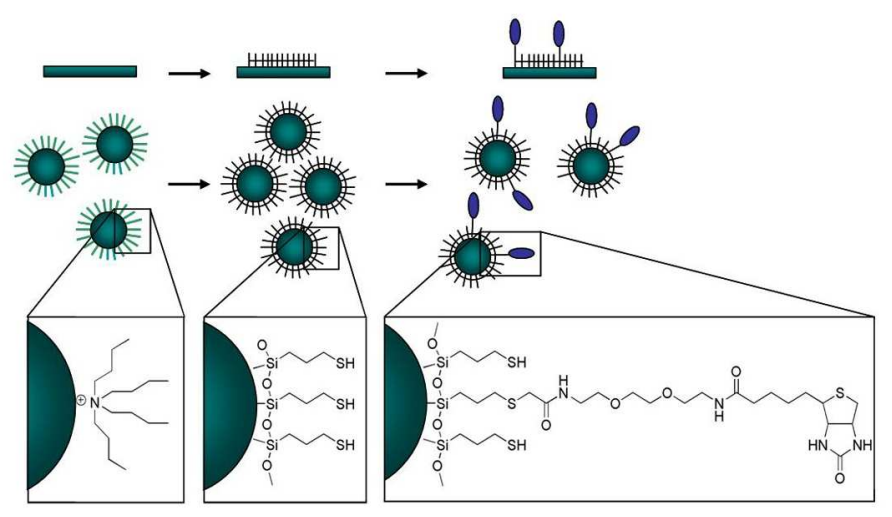

Figure 17. Schematic picture of the functionalization steps of $\mathrm{ZnO}$ nanoparticles and films (redrawn from (77)). 


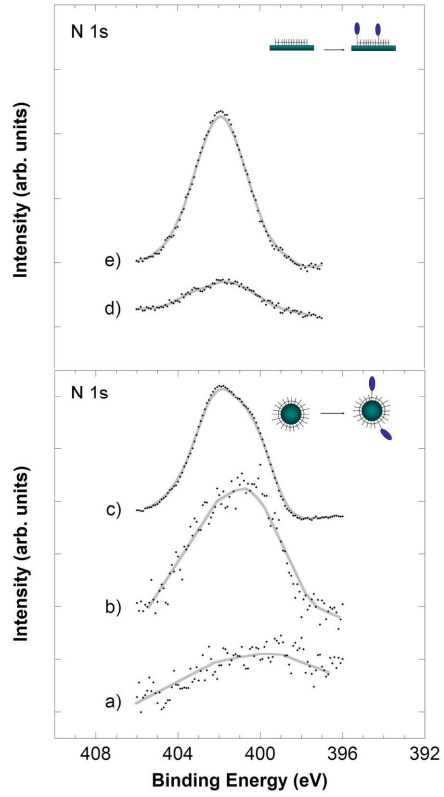

Figure 18. $\mathrm{N}$ (1s) XPS core level spectra for a) $\mathrm{ZnO}$ nanoparticles functionalized with MPTS b) MPTS/PEG2-biotin functionalized $\mathrm{ZnO}$ nanoparticles c) multi layer of iodoacetyl-PEG2-biotin d) MPTS functionalized $\mathrm{ZnO}$ film and e) $\mathrm{ZnO}$ film functionalized with MPTS/PEG2-biotin (redrawn from (77)). Inserted in the upper right corners are schematic pictures of functionalization strategy on $\mathrm{ZnO}$ film and functionalization of nanoparticles, respectively.

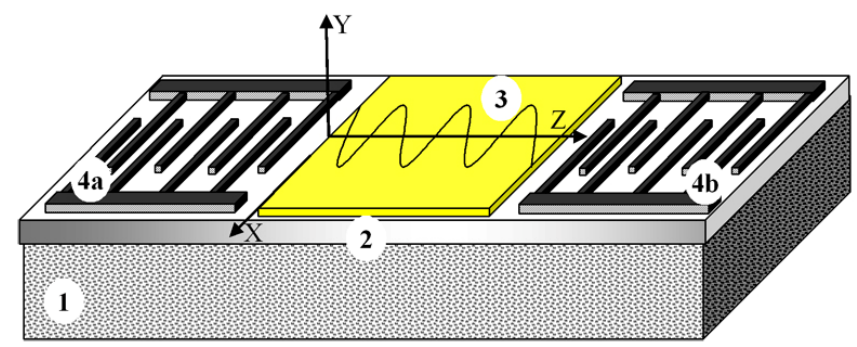

Figure 19. Schematic of a typical SAW biosensor, operating in shear-horizontal surface acoustic waves (SH-SAW) mode. The device consists of: substrate (1); piezoelectric film (f. e. $\mathrm{ZnO}$ ) with specific texture (2); biologically functionalized layer (3); interdigital input (4a) and output (4b) electrodes. The waves have a displacement that is parallel to the device's surface (X-Z plane).

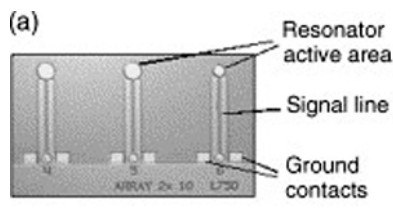

(b)

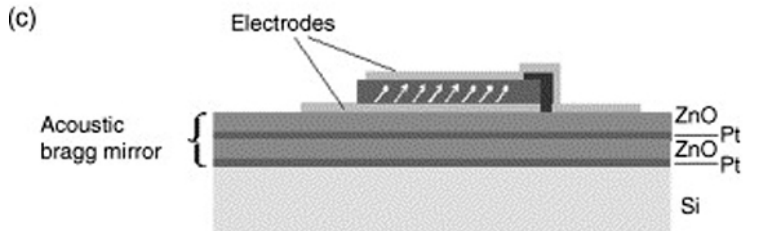

Figure 20. Setup of the FBAR biosensor: (a) top view of the resonator and the electrical leads, (b) electron microscope picture of $\mathrm{C}$-axis inclined $\mathrm{ZnO}$ and (c) schematic picture of the lateral structure comprising the resonator with two electrodes solidly mounted on an acoustic Bragg mirror. Reprinted from J Weber, W Albers, J Tuppurainen, M Link, R Gabl, W Wersing, M Schreiter: Shear mode FBARs as highly sensitive liquid biosensors. Sens Actuat A 128, $84-88$ (2006) with permission from Elsevier. 